This document is the accepted manuscript version of the following article: Vitul1o, F., Krepel, J., Kalilainen, J., Prasser, H. M., \& Pautz, A. (2019). Statistical burnup distribution of moving pebbles in the HTR-PM reactor. Journal of Nuclear Engineering and Radiation Science. https://doi.org/10.1115/1.4044910

\title{
Statistical burnup distribution of moving pebbles in the HTR-PM reactor
}

\author{
Fanny Vitullo* \\ Paul Scherrer Institut (PSI), \\ 5232 Villigen, Switzerland \\ École Polytechnique Fédérale de \\ Lausanne (EPFL), 1015 Lausanne, Switzerland \\ Email: fanny.vitullo@epfl.ch \\ Jarmo Kalilainen \\ Paul Scherrer Institut (PSI), \\ 5232 Villigen, Switzerland \\ Email: jarmo.kalilainen@psi.ch
}

\author{
Jiri Krepel \\ Paul Scherrer Institut (PSI), \\ 5232 Villigen, Switzerland \\ Email: jiri.krepel@psi.ch
}

\author{
Horst-Michael Prasser \\ Paul Scherrer Institut (PSI), \\ 5232 Villigen, Switzerland \\ ETH Zürich, 8092 Zürich, Switzerland \\ Email: prasser@lke.mavt.ethz.ch
}

\author{
Andreas Pautz \\ Paul Scherrer Institut (PSI), \\ 5232 Villigen, Switzerland \\ École Polytechnique Fédérale de Lausanne (EPFL) \\ 1015 Lausanne, Switzerland \\ Email: andreas.pautz@epfl.ch
}

\begin{abstract}
In the pebble-bed high temperature reactor under construction in China, called the HTR-PM, the spherical fuel elements continuously flow downward in the cylindrical core. The burnup of each pebble is checked at the core outlet and, according to the achieved burnup level, the pebble might be disposed or reinserted into the upper section of the core. Upon reinsertion, each pebble is radially distributed in a random manner and, according to its downward path, faces different burnup conditions. Hence, the number of passes necessary to achieve the average discharge burnup of $90 \mathrm{MWd} / \mathrm{kg} U$ may vary. Discrete Element Method (DEM) simulations have been carried out to achieve a clear understanding of the movement of the 420,000 fuel pebbles in the HTR-PM core. At the same time, neutronics properties have been investigated for a single pebble and for the full core with the Serpent 2 Monte Carlo code. As a result, one-group microscopic cross sections have been parametrized at the core level. The pebble movement has been loosely coupled with the depletion of a single pebble in a dedicated burnup script called Moving Pebble Burnup (MPB), developed in Matlab. 3,000 single pebble burnup histories were simulated to obtain sufficient statistics and an insight into the HTR-PM burnup process. The decrease of the average burnup gained per single pass implies that a miss-handling of recirculated fuel elements is unlikely to lead to an excess of the maximum allowed burnup of $100 \mathrm{MWd} / \mathrm{kgU}$. The core demonstrates a self-compensation effect of burnup, meaning that it always compensates burnup under- or over-runs in the successive passes. In addition, gamma detection of ${ }^{137}$ Cs has been studied as a practical method for monitoring the burnup of the discharged pebbles, turning out to be an applicable measurement technique. Finally, it is possible to conclude that the fuel cycle of the HTR-PM, as it has been laid out, is well-designed and feasible.
\end{abstract}

\footnotetext{
${ }^{*}$ Address all correspondence related to ASME style format and figures to this author.
} 


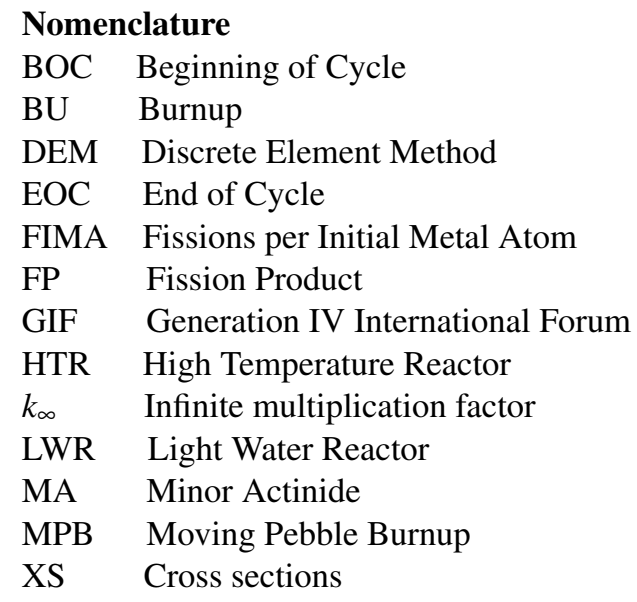

\section{Introduction}

The promising concept of pebble-bed high temperature reactors (HTRs) is nowadays investigated in the framework of Generation IV International Forum (GIF). The first HTR designs were developed in the early nuclear history and recently this technology has been receiving a significant renewed interest due to its improved safety and the possible industrial applications, such as hydrogen production. The low power density, combined with the multi-level barriers of the TRISO particles, ensures a strong enhancement of the safety features [1,2], allowing design simplifications and costs reductions. However, the HTR technology is less sustainable form the fuel cycle point of view compared to other reactor designs [3].

The HTR-PM reactor, under construction in China since 2012, represents the actual state of the art of the pebble-bed HTRs technology. The plant is composed by two reactor modules of 250 MWth coupled with a 210 MWe steam turbine. Each module consists of a graphite-moderated, helium-cooled pebble-bed reactor core, with thermal neutron spectrum $[2,4]$. On the contrary of light water reactors (LWRs), the distinguish feature of this reactor design are the 420,000 moving spherical fuel elements, which continuously flow in the core and might be recirculated or disposed according to the achieved burnup level. Moving pebbles face different burnup conditions during the multi-pass fuel loading scheme depending on their path and thus the number of passes necessary to achieve the average discharge burnup of $90 \mathrm{MWd} / \mathrm{kgU}$ may vary. The burnup limit that must not be exceeded for safety reasons is set to $100 \mathrm{MWd} / \mathrm{kgU}$ [4].

In graphite-moderated environments, the neutron migration length is larger compared to LWRs. Hence, the neutron spectrum of a single pebble is predominantly determined by the surrounding pebbles. At the same time, in an equilibrium core, where pebbles with different burnup states are randomly mixed, a single fuel element cannot influence the total power and the flux level of the core. Therefore, each pebble will face the same flux level in a given area, independently from its history. The strong influence of the global core properties implies that the one-group microscopic cross sections (XS) necessary for the solution of the Bateman equations must be generated at core-level using average core properties and the flux level must be fixed and generated by a full-core simulation. The generation of cross sections for a single pebble in a real average core geometry differs from the standard procedure employed by most neutronics commercial codes that would generate cross sections for pebbles in an infinite lattice.

At the same time, a clear understanding of the dense granular flow of pebbles in the HTR-PM reactor is necessary to safely operate the reactor. Studying the exact flow paths allows also building explicit models and performing dynamic burnup simulations. The problem of the simultaneous account for the pebble movement and the fuel composition evolution has been studied in the past with different levels of approximation. Deterministic codes as VSOP (Very Superior Old Programs) [5] and PEBBED [6], both based on the diffusion approximation, were developed in the past to track batches of pebbles in successive layers of simplified core geometries. With the advent of stochastic approaches, Monte Carlo-based codes as MCPBR [7] have been investigated because of their ability to discard the diffusion approximation and model the double heterogeneity and the randomly packed pebble-bed typical of HTR cores.

The goals of the current work are to:

- Calculate the exact pebble trajectories in the HTR-PM core with Discrete Element Method (DEM) simulations.

- Parametrize one-group microscopic cross sections with continuous-energy Monte Carlo code Serpent 2 on the full-core level. The cross section parametrization is preceded by sensitivity studies on different parameters (flux level, burnup state, pebble temperature, and graphite proximity) affecting one-group microscopic cross sections on cell-level and core-level.

- Loosely couple the pebble movement with the burnup of a single pebble, employing the cross sections previously generated and parametrized with Serpent 2. The coupling is performed with a specifically developed Matlab script, called Moving Pebble Burnup (MPB). 
- Perform statistic evaluations and draw conclusions on the multi-pass fuel loading scheme of the HTR-PM reactor from the simulation of the burnup behaviour of 3,000 single pebbles with the MPB script.

The upcoming sections are structured accordingly. First, pebble movement simulations are briefly described, followed by the construction of the models in Serpent 2 and the sensitivity studies of one-group microscopic cross sections at the cell-level and core-level. Afterwards, cross sections under the form of burnup matrices are generated and parametrized at the core level. In the end, the MPB script is described and the statistical results are analyzed to draw conclusions on the HTR-PM fuel cycle.

\section{Pebble movement simulations}

The lack of theoretical models and the not straightforward experimental research on the topic of granular flows lead to the development of three-dimensional full-scale simulations that are suitable to study the pebble movement in HTRs.

As of today, it is possible to carry out large scale simulations of the continuous pebble flow with Discrete Element Methods (DEM). Most of the pebble-bed reactor types in operation have been analyzed using DEM-like methods. Commercial packages as PFC3D [8] and appositely developed codes like PEBBELS [9] have been used for the comprehensive study of the movement of fuel pebbles in the PBMR-400 reactor design. In the current work, the approach preferred is the one developed by Rycroft et al. [10] at Paul Scherrer Institut (PSI). Movements and interactions of pebbles are simulated in details with the Large Atomic/Molecular Massively Parallel Simulator, commonly called LAMMPS.

The already existing in-house LAMMPS input model, developed for scaled HTR reactor designs by Rycroft et al. [10] and readily available at PSI, has been modified in order to represent the actual full-scale HTR-PM geometry. The LAMMPS code tracks and updates the position, the velocity and the angular velocity of each of the 420,000 pebbles in the HTR-PM core at every time step. The mentioned quantities evolve according to the Newton's second law and to a modified version of the particle contact model developed by Cundall and Strack in 1979 [10,11]. The latter linearly relates displacement and exerted forces through a series of dimensionless parameters, reported in Tab.1.

Table 1: Dimensionless parameters used for the pebble contact model in LAMMPS [2, 10].

\begin{tabular}{ll}
\hline Simulation dimensionless parameter & Value \\
\hline Number of pebbles & 420,000 \\
Pebble diameter $D$; pebble mass $M$; gravity $G$ & 1 \\
Pebble density $\rho$ & 1.9099 \\
Normal elastic constant $K_{n}$ & $2 \times 10^{6} M G / D$ \\
Tangential elastic constant $K_{t}$ & $(2 / 7) K_{n}$ \\
Normal dumping constant $\Gamma_{n}$ & 2021.8 \\
Tangential dumping constant $\Gamma_{t}$ & $(1 / 2) \Gamma_{n}$ \\
Friction coefficient $\mu$ & 0.5 \\
Timesteps & $2.5 \times 10^{-5}$ \\
\hline
\end{tabular}

The input parameters in Tab.1 were adopted to simulate first the pouring of the 420,000 pebbles to fill the HTR-PM core and then the draining of pebbles at the core outlet with their subsequent reinsertion in the upper section. Figure 1 depicts an example of a snapshot taken during the draining simulations along a vertical cut of the HTR-PM core. The color bands highlighting the pebble flow suggest a uniform velocity profile in the reactor bulk with pebbles diffusing less than one diameter along their path, as already proved by Kadak and Bazant [12], and show the presence of an external boundary layer where pebbles move slowly due to the friction exerted by the graphite wall. No stagnation zones can be spotted during the draining simulation.

The simulation outcome consists on the position of the 420,000 pebbles every 80,000 timesteps. Knowing the position of each pebble in time, it is possible to reconstruct single pebble trajectories throughout the reactor core. For the sake of simplicity, eleven representative trajectories (shown in Fig. 2) have been sampled for further studies. Each of the eleven trajectories represents the average pebble movement in a concentric zone of the HTR-PM reactor core (see Fig. 3a). The radial zones have a width of $15 \mathrm{~cm}$, except for the two zones closer to the graphite reflector ( 9 and $6 \mathrm{~cm}$ of width respectively) defined as such in order to better describe the slow-moving boundary layer of pebbles. The trajectories of the three concentric zones near the graphite reflector have been reconstructed by joining the path of different pebbles because it was not possible 
to record the full pebble movement in those zones during the performed simulation due to the lower pebble speed compared to the core bulk. The pebble residence time and average speed in each zone have been calculated by averaging 200 trajectories per zone and then they have been rescaled from the simulation time to the real time knowing the real discharge rate of pebbles in the HTR-PM equal to 4.2 pebbles/min [13]. The average values per zone, shown in Tab. 2, have been assigned to the 11 representative trajectories.

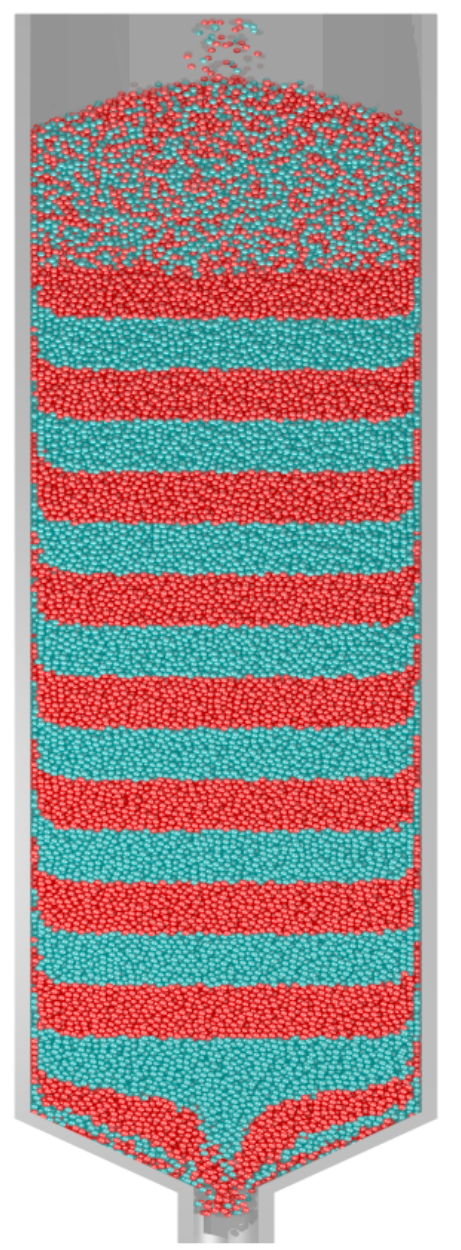

Fig. 1: Example of a snapshot taken in a vertical cut through the central axis of the full-size HTR-PM core geometry. The different color bands are used to highlight the pebble flow.

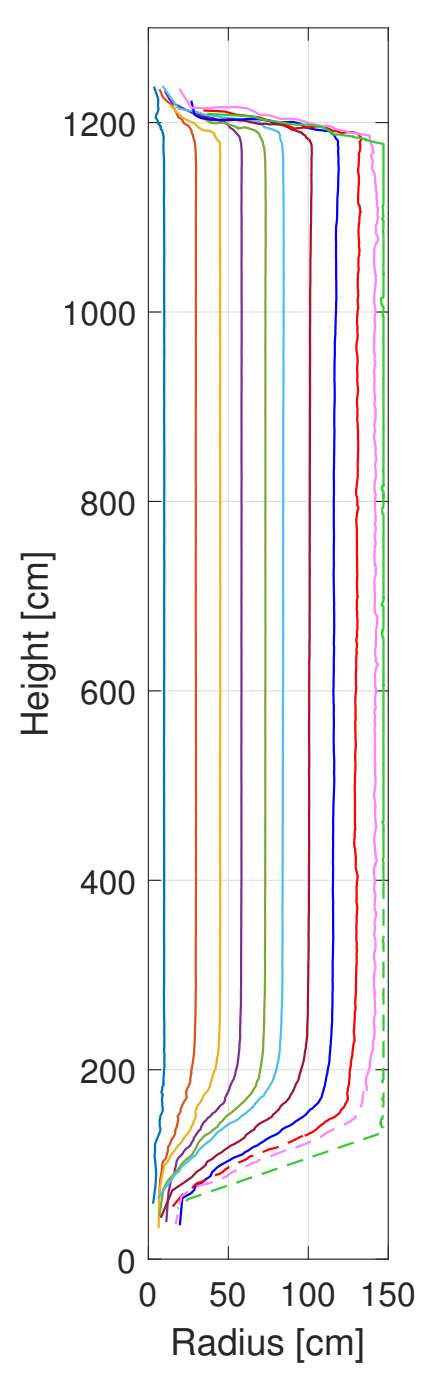

Fig. 2: Illustration of the 11 selected trajectories, each representative of a concentric reactor zones. Dashed lines are full trajectories reconstructed from partial trajectories.

Every time a pebble is reinserted in the core upper section, it ends randomly in one of the designated 11 concentric zones according to a specific probability distribution function. The probability distribution function, shown in Fig. 3b, has been built assuming that the pebble volumetric flow rate in each region is constant and equal to the product of the average pebble velocity in the concentric zone and the area of the zone. The probability of each single zone comes from the division of its volumetric flow rate by the total flow rate in the whole core horizontal section. Considering a 15-pass fuel loading scheme [14], the probability that one pebble will always go through the central zone is in the order of $10^{-30}$, whereas the probability that it will always flow in the outermost region is $10^{-19}$. Therefore, being the two extreme cases very unlikely, pebble histories consist of combinations of passes through different core zones. 
Table 2: Scaled average pebble residence time and speed for the 11 concentric zones expressed in real time. Values marked with * refer to reconstructed trajectories.

\begin{tabular}{cccc}
\hline Zone & $\begin{array}{c}\text { Radial width } \\
{[\mathbf{c m}]}\end{array}$ & $\begin{array}{c}\text { Average residence time } \\
\text { [days] }\end{array}$ & $\begin{array}{c}\text { Average speed } \\
{\left[\mathbf{1 0}^{-\mathbf{4}} \mathbf{~} \mathbf{c m} / \mathbf{s}\right]}\end{array}$ \\
\hline 1 & 15 & $64.3 \pm 0.2$ & $1.84 \pm 0.14$ \\
2 & 15 & $64.3 \pm 0.2$ & $1.84 \pm 0.14$ \\
3 & 15 & $64.6 \pm 0.2$ & $1.84 \pm 0.14$ \\
4 & 15 & $65.1 \pm 0.2$ & $1.84 \pm 0.14$ \\
5 & 15 & $65.7 \pm 0.2$ & $1.84 \pm 0.14$ \\
6 & 15 & $66.3 \pm 0.3$ & $1.84 \pm 0.14$ \\
7 & 15 & $67.8 \pm 0.3$ & $1.84 \pm 0.14$ \\
8 & 15 & $68.4 \pm 0.3$ & $1.84 \pm 0.14$ \\
9 & 15 & $71.0^{*}$ & $1.84^{*}$ \\
10 & 9 & $75.8^{*}$ & $1.77^{*}$ \\
11 & 6 & $104.9^{*}$ & $1.32^{*}$ \\
\hline
\end{tabular}

(a)

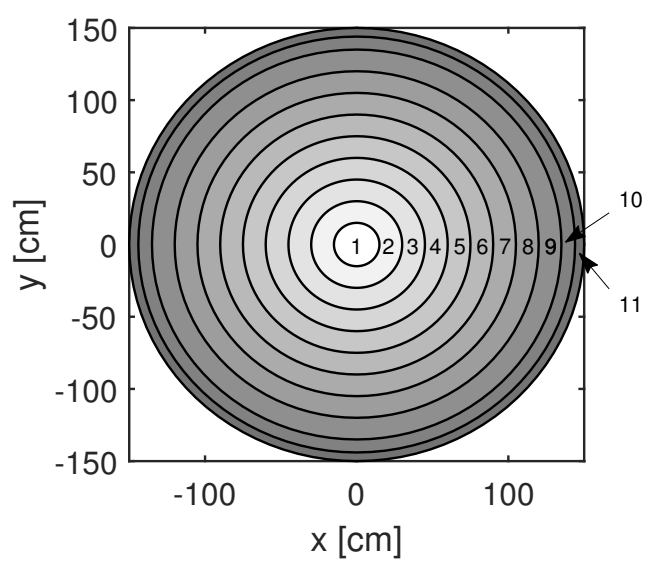

(b)

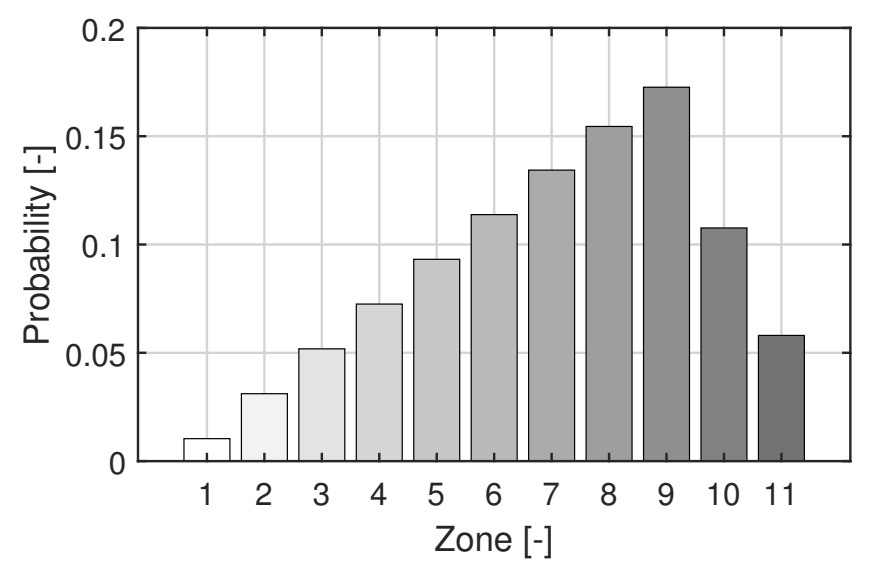

Fig. 3: (a) Illustration of the 11 concentric zones in a horizontal cut of the HTR-PM reactor core. (b) Probability distribution function for the 11 radial zones.

\section{Neutronics modelling with the Serpent 2 Monte Carlo code}

In this study, neutronics calculations have been carried out with the 3D continuous energy Monte Carlo code Serpent 2 [15]. The Serpent 2 code has been chosen due to its particular suitability for handling randomly-distributed fuel particles and fuel elements, which makes it a perfect choice for the modeling of the double heterogeneous geometry typical of HTR reactors without major approximations. The ENDF/B-VII.0 cross sections data library [16] is used for all the neutronics simulations performed in this work.

\subsection{Cell-level model}

A single fresh pebble, with the characteristics described in Tab. 3, has been modeled as shown in Fig. 4a and 4b with the Monte Carlo code Serpent 2. TRISO particles positions have been generated with a Serpent routine that randomly disperses coated particles in a spherical volume. The single pebble has been burned along the full burnup history of the HTR-PM reactor, namely from $0 \mathrm{MWd} / \mathrm{kgU}$ up to the maximum allowed burnup of $100 \mathrm{MWd} / \mathrm{kgU}$, passing through the average discharge burnup value of $90 \mathrm{MWd} / \mathrm{kgU}$. The periodic boundary conditions in all the directions define an infinite square lattice of pebbles. The modeled configuration is not representative of the real reactor bulk, in which neighboring pebbles have different burnup and are randomly packed. Nevertheless, cell-level sensitivity studies give an insight on the effect of some parameters such as burnup level, flux level and pebble temperature on the one-group microscopic cross sections during 
the depletion process. All the sensitivity studies at the cell-level have been performed with Serpent 2 criticality simulations, using 5,000 neutrons per generation, 500 active cycles and 50 inactive cycles per burnup step.

(a)

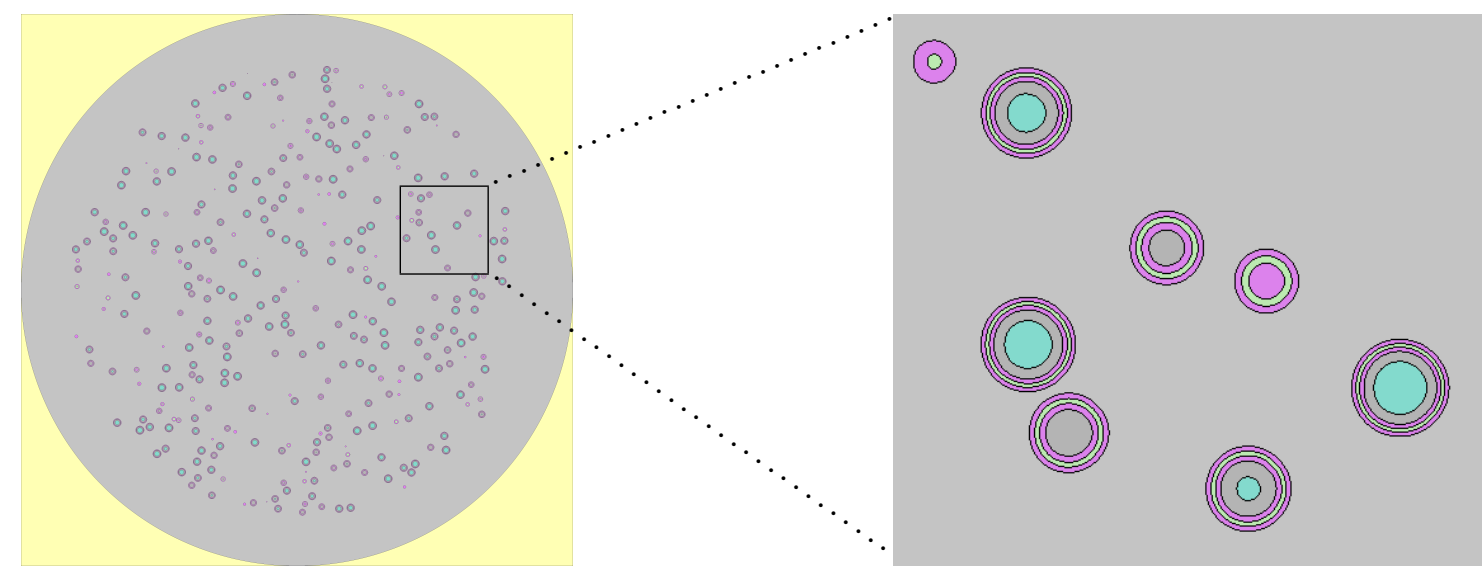

Fig. 4: (a) Cross cut of HTR-PM single pebble modelled in Serpent 2 with reflective boundary conditions. (b) A magnification of the TRISO particles randomly dispersed into the pebble graphite matrix.

Table 3: TRISO particles and pebble features in the HTR-PM core [2, 14, 17].

\begin{tabular}{ll}
\hline Parameters & Value \\
\hline $\mathrm{UO}_{2}$ fuel density $\left[\mathrm{g} / \mathrm{cm}^{3}\right.$ ] & 10.4 \\
Enrichment of fresh fuel element [\%] & 8.6 \\
Fuel natural boron impurity by mass [ppm] & 1 \\
Outer coated particle radius [cm] & 0.046 \\
Fuel kernel radius [cm] & 0.025 \\
Coating materials [-] & $\mathrm{C} / \mathrm{IPyC} / \mathrm{SiC} / \mathrm{OPyC}$ \\
Coating thicknesses [cm] & $0.0095 / 0.004 / 0.0035 / 0.004$ \\
Coating densities [g/cm ${ }^{3}$ ] & $1.05 / 1.9 / 3.18 / 1.9$ \\
Heavy metal loading per fuel element [g] & 7 \\
Number of TRISO particles per pebble [-] & $\sim 11,660$ \\
Pebble diameter [cm] & 6 \\
Graphite layer thickness [cm] & 0.5 \\
Average fuel/pebble temperature [ $\left.{ }^{\circ} \mathrm{C}\right]$ & 600 \\
Number of pebbles in the core $[-]$ & 420,000 \\
Fuel loading scheme [-] & 15 passes \\
Average discharge burnup [MWd/kgU] & 90 \\
Maximum discharge burnup [MWd/kgU] & 100 \\
\hline
\end{tabular}

As already discussed, each pebble flows from the top to the bottom of the core facing different neutron flux levels and fuel temperatures along its path and it is then reinserted to start the next pass. The HTR-PM fuel loading scheme of a single pebble has been assumed to be a 15-pass scheme [14] with equal burnup steps of $6 \mathrm{MWd} / \mathrm{kgU}$ lasting one fifteenth of the total pebble residence time in the core, as in Fig. 5. This burnup scheme represents a first estimate of the depletion procedure during the multiple passes through the HTR-PM core. However, the number of passes might vary depending on the single 
pebble history and the burnup steps might have different lengths. According to Fig. 5, an average fuel composition at the half-core height has been calculated making use of the burnup of a single pebble in infinite lattice by averaging all the isotopic compositions at mid-core. The resulting average isotopic composition corresponds to the burnup level of $45 \mathrm{MWd} / \mathrm{kgU}$.

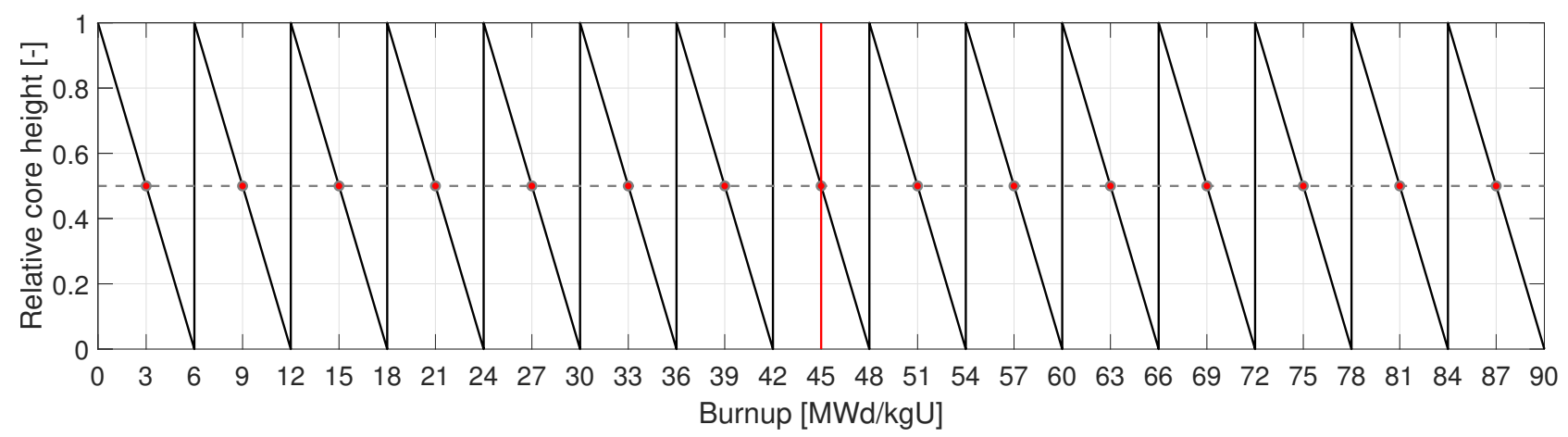

Fig. 5: HTR-PM fuel loading scheme assumed to be a 15-pass scheme with equal burnup step length. The red line indicates the calculated average fuel composition as an average of the compositions corresponding to the red dots.

The geometry for a single pebble in infinite lattice has been extended into a cube with reflective boundary conditions filled with a square lattice of $5 \times 5 \times 5$ pebbles. The pebbles contain TRISO particles filled with fuel of average composition, except for the central pebble that is depleted from 0 to $90 \mathrm{MWd} / \mathrm{kgU}$. The number of pebbles in every direction was chosen as a compromise between the need for results with acceptable uncertainties and the necessity to have a minimal distance equal to one diffusion length between the central depleted pebbles. A single Serpent burnup calculation has been performed using 100,000 neutrons per generation, 1,000 active cycles and 200 inactive cycles per burnup step in order to improve statistics. Although the random packing of pebbles is not taken into account, the modeled configuration provides a good approximation of the burnup process of a single pebble in the HTR-PM core, where each of the 420,000 pebbles is depleted while surrounded by other pebbles with different burnup that share the same neutron spectrum.

\subsection{Core-level model}

The full-size HTR-PM core has been modeled in Serpent 2, with an active core diameter and a height of $3 \mathrm{~m}$ and $11 \mathrm{~m}$ respectively [2] and a graphite reflector with a thickness equal to $50 \mathrm{~cm}$. The 420,000 fuel pebbles are positioned explicitly in the core taking advantage of the properly scaled pebble coordinates obtained at the end of the pouring simulation performed with the LAMMPS code. From the modelling of the full HTR-PM core and the knowledge of the average fuel composition, it is possible to perform an additional sensitivity study to investigate the effect of the graphite reflector proximity on one-group microscopic cross sections. At the same time, the neutron flux map is computed for the full-core entirely filled with pebbles with an average fuel composition and at the constant fuel temperature of $900 \mathrm{~K}$. A Serpent 2 simulation has been performed for the full-core model with 10,000 neutrons per cycle, 1,000 active cycles and 100 inactive cycles.

In addition, cross sections under the form of sets of burnup matrices have been generated and parametrized at the core level. The parametrization has been realized according to previously performed sensitivity studies and it is extensively discussed in Section 5. The knowledge of burnup matrices, combined with the calculation of the flux profile in the core, allows the solution of the Bateman equations for a single pebble moving through the HTR-PM core.

\section{Analysis of cross sections sensitivity}

Cross sections sensitivity studies require preliminary cell-level calculations with Serpent 2 to investigate the trends of the infinite multiplication factor $\left(k_{\infty}\right)$, the neutron flux and the fuel mass composition along the burnup.

Cell-level burnup calculations have been carried out setting either the power or the neutron flux as a constant parameter during the fuel depletion. When a single pebble is burned at its constant average power of $0.6 \mathrm{~kW}_{\text {th }}$ as presented in Fig. $6 \mathrm{a}$, an increase in the neutron flux is necessary to compensate the decrease of the macroscopic cross sections of fissile atoms in order to maintain the desired constant power level. It is possible to calculate the average constant neutron flux equal to $3.325 \times 10^{16} \frac{1}{\mathrm{~cm}^{2} s}$. The following sensitivity studies have been performed based on this calculated reference value because in a real scenario the pebble neutron flux remains constant while the pebble power decreases during burnup. Hence, it is reasonable to think that the burnup that a single pebble would gain at each pass will decrease. Nonetheless, the first estimate of the HTR-PM burnup scheme and the derived average composition were kept as assumed in Fig. 5. The evolution of 
the infinite multiplication factor shown in Fig. $6 \mathrm{~b}$ for the two burnup cases presents a slightly faster depletion towards 100 $\mathrm{MWd} / \mathrm{kgU}$ when the single pebble is burned at constant neutron power due to the increase of the neutron flux (see Fig. 6a).

The evolution of the fuel mass composition during burnup is presented in Fig. 7 for a single pebble burned at constant power up to the average discharge burnup equal to $90 \mathrm{MWd} / \mathrm{kgU}$ and corresponding to the end of cycle (EOC). The fuel composition at the EOC for the two burnup cases is shown in Tab. 4. The two final compositions show differences within less than $1 \%$, except for the minor actinides composition that differs by $-3 \%$ due to the higher build-up of those elements at increasing flux levels.

(a)

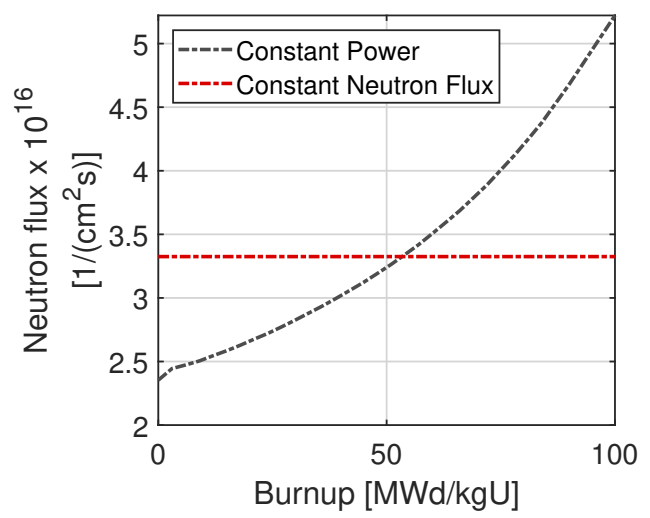

(b)

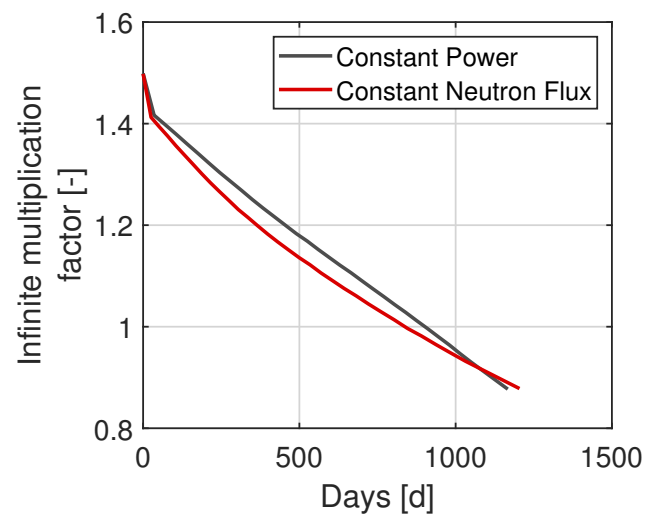

Fig. 6: Neutron flux (a) and infinite multiplication factor $k_{\infty}$ (b) evolution during the burnup of a single pebble at constant power or at constant neutron flux. Statistical uncertainties are below $1 \%$ and thus they are not shown.

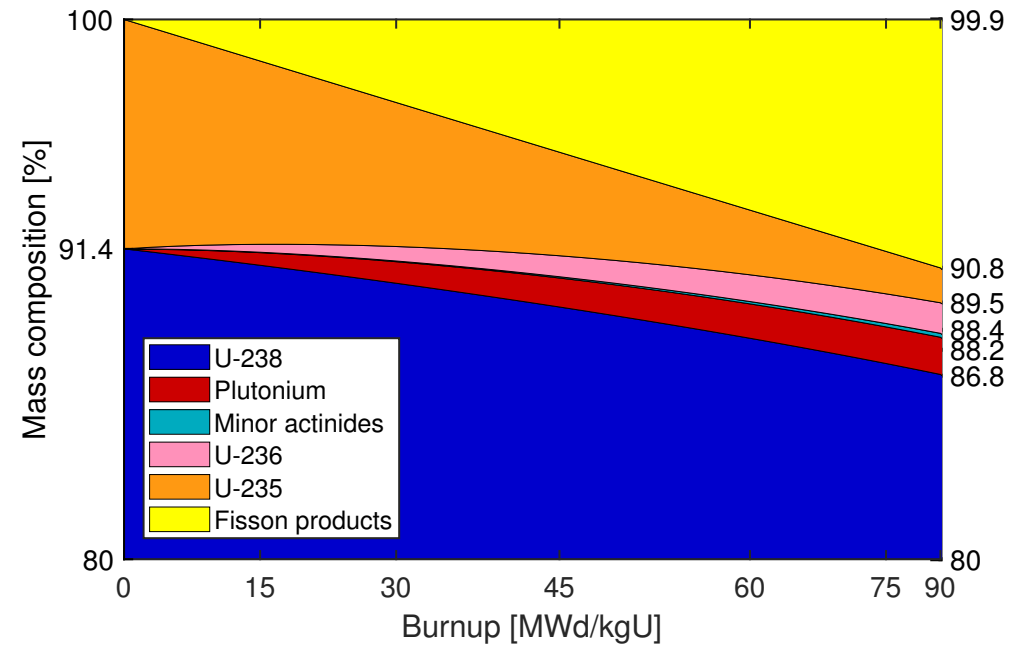

Fig. 7: Mass composition evolution during the burnup of a single pebble in infinite lattice burned at constant power.
Table 4: Fuel composition evolution at $0 \mathrm{MWd} / \mathrm{kgU}$ (BOC) and $90 \mathrm{MWd} / \mathrm{kgU}$ (EOC) for single pebble burnup at constant power and constant neutron flux.

\begin{tabular}{cccc}
\hline & BOC & EOC $_{\text {power }}$ & EOC $_{\text {flux }}$ \\
\hline${ }^{238} \mathrm{U}$ & $91.4 \%$ & $86.8 \%$ & $86.8 \%$ \\
$\mathrm{Pu}$ & - & $1.38 \%$ & $1.38 \%$ \\
$\mathrm{MAs}$ & - & $0.15 \%$ & $0.14 \%$ \\
${ }^{236} \mathrm{U}$ & - & $1.13 \%$ & $1.13 \%$ \\
${ }^{235} \mathrm{U}$ & $8.6 \%$ & $1.29 \%$ & $1.30 \%$ \\
$\mathrm{FPs}$ & - & $9.2 \%$ & $9.2 \%$ \\
\hline
\end{tabular}

\subsection{Sensitivity to the flux level}

The approach employed to evaluate the cross sections sensitivity to the flux level consists in the variation of the reference value of the average neutron flux. Doubling the neutron flux level, a single pebble burns up twice faster compared to the reference case, while the depletion time is halved if the flux is set to half the nominal flux value. The pebble temperature is maintained constant at $900 \mathrm{~K}$. One-group microscopic cross sections for fission and capture of the main actinides $\left({ }^{235} \mathrm{U}\right.$, ${ }^{236} \mathrm{U},{ }^{238} \mathrm{U},{ }^{239} \mathrm{Pu}$ and ${ }^{240} \mathrm{Pu}$ ), normalized to their reference value at $100 \%$ neutron flux, were calculated by means of reaction rate and flux detectors in Serpent 2 at the HTR-PM average discharge burnup of $90 \mathrm{MWd} / \mathrm{kgU}$. The results are presented in 
Fig. 8. Flux level changes have a limited impact on the microscopic cross sections, with variations within $1 \%$. Hence, the fluctuations of the flux level can be discarded from the parameter affecting the one-group microscopic cross sections of a single pebble in an infinite lattice.
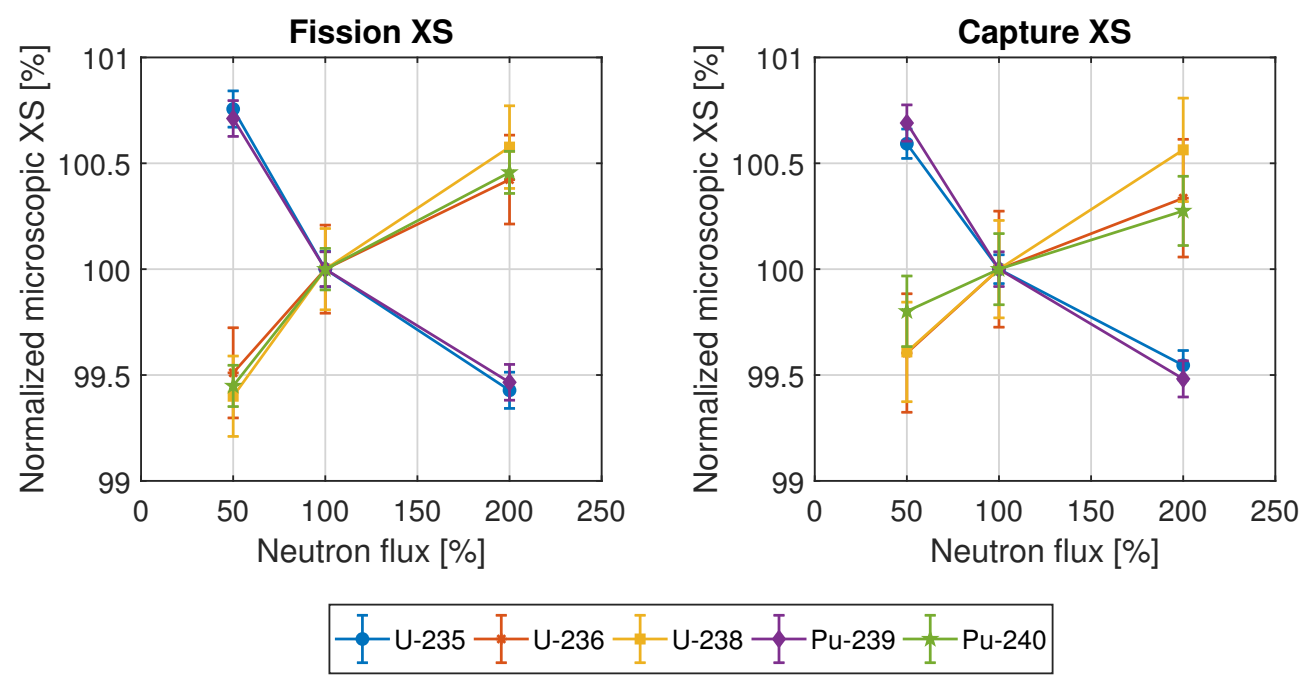

Fig. 8: Flux sensitivity at $50 \%$ and $200 \%$ of the nominal flux for normalized one-group microscopic fission and capture XS for ${ }^{235} \mathrm{U},{ }^{236} \mathrm{U},{ }^{238} \mathrm{U},{ }^{239} \mathrm{Pu}$ and ${ }^{240} \mathrm{Pu}$ at $90 \mathrm{MWd} / \mathrm{kgU}$. The pebble temperature is set to $900 \mathrm{~K}$.

\subsection{Sensitivity to the burnup state}

The evolution of the fuel composition during the fuel depletion may affect the one-group microscopic cross section values. In order to evaluate their sensitivity to the burnup state, one group microscopic cross sections were calculated with the same approach described before for the five main actinides present in the fuel at the nominal pebble temperature of 900 $\mathrm{K}$ and at the increased temperature of $1200 \mathrm{~K}$. The fission cross section trends, normalized to their value for the fresh fuel, are reported in Fig. 9 along with the relative differences between the two temperature cases. Capture cross sections behave similarly.
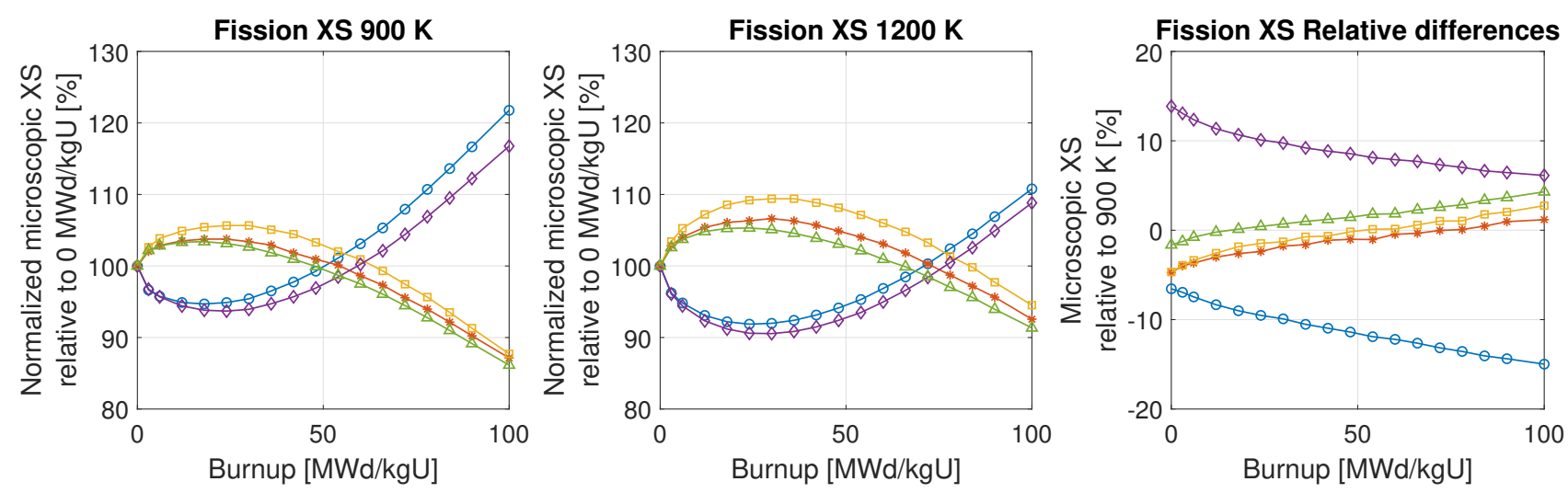

$\rightarrow \mathrm{U}-235 \rightarrow \mathrm{U}-236 \rightarrow \mathrm{U}-238 \rightarrow \mathrm{Pu}-239 \rightarrow \mathrm{Pu}-240$

Fig. 9: Evolution of normalized one-group microscopic fission $\mathrm{XS}$ of ${ }^{235} \mathrm{U},{ }^{236} \mathrm{U},{ }^{238} \mathrm{U},{ }^{239} \mathrm{Pu}$ and ${ }^{240} \mathrm{Pu}$ along the burnup (from 0 to $100 \mathrm{MWd} / \mathrm{kgU}$ ) at constant neutron flux and pebble temperature of $900 \mathrm{~K}$ (on the left) and $1200 \mathrm{~K}$ (in the center). On the right, relative differences between the two cases are shown. Uncertainties are smaller than $0.3 \%$ and thus error bars are not displayed.

For a single pebble in an infinite square lattice, fission cross sections vary up to $\pm 22 \%$ as visible in Fig. 9. The 
explanation to the peculiar trend of the cross sections along the burnup can be found in the evolution of the normalized neutron spectrum between 0 and $100 \mathrm{MWd} / \mathrm{kgU}$, reported in Fig. 10a. The neutron spectrum, whose area under the curve is constant due to the constant neutron flux assumption, presents a decrease of the thermal peak between 0 and $30 \mathrm{MWd} / \mathrm{kgU}$ and then an increase up to $100 \mathrm{MWd} / \mathrm{kgU}$. Two spectral indices have been defined for the the thermal and the fast regions in Eqn. (1) and Eqn. (2) respectively:

$$
\begin{gathered}
S I_{\text {thermal }}=\frac{\text { Area under spectrum below } 1 \mathrm{eV}}{\text { Total area under spectrum }} \\
S I_{\text {fast }}=\frac{\text { Area under spectrum above } 1 \mathrm{eV}}{\text { Total area under spectrum }}
\end{gathered}
$$

(a)

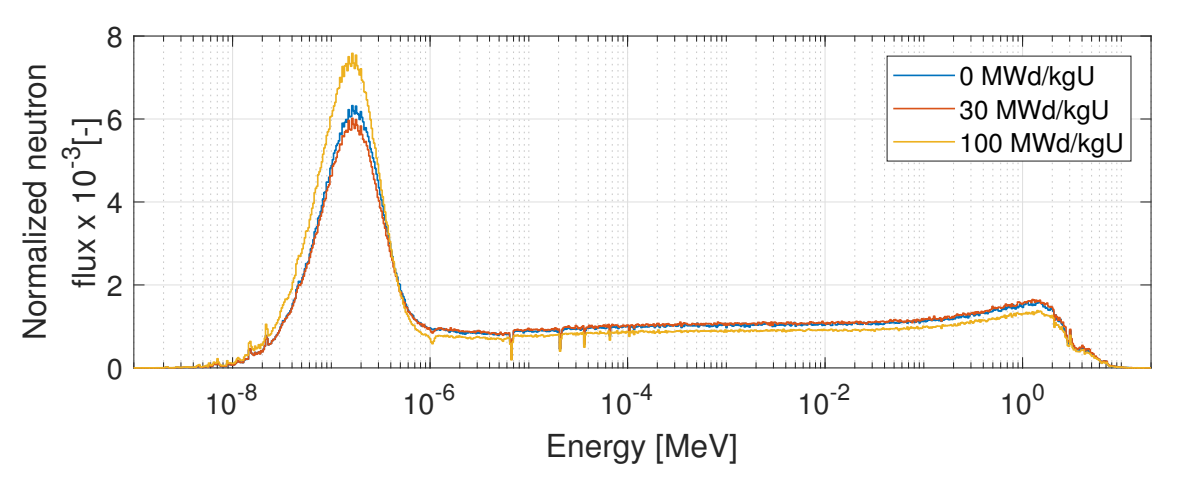

(b)

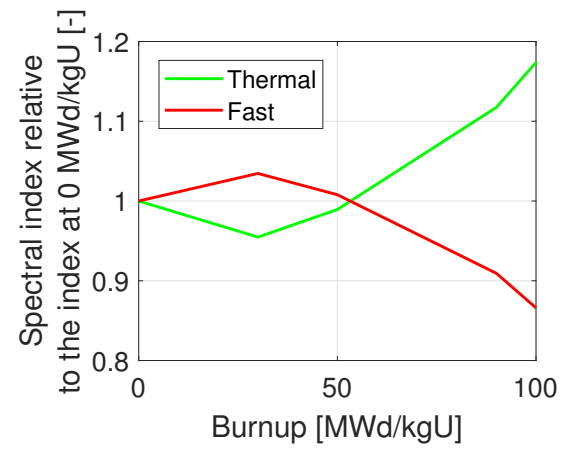

Fig. 10: (a) Normalized neutron spectrum of a single pebble at different burnup stages during the burnup at constant neutron flux and at nominal temperature equal to $900 \mathrm{~K}$. Uncertainties are below 2\%. (b) Spectral indices plot calculated for the same spectrum at $900 \mathrm{~K}$.

The spectral indices values are plotted in Fig. 10b, normalized with respect to the value of the fresh fuel. The trend of the spectral indices confirms the consecutive drop and rise of the thermal peak of the neutron spectrum and it shows a barely visible increase and then decrease of the fast peak. In addition, Fig. 10b shows that the cross section trend illustrated in Fig. 9 is linked to the spectral changes. In the early burnup stages the spectrum variation is caused by self-shielding effects given by the build-up of plutonium, which consumes thermal neutrons and increases the share of fast neutrons produced after fission. As a consequence, fissile elements show a drop in the one-group microscopic cross section average value correspondent to the fall of the thermal flux and to the growth of the fast component. In the long run, all fissile materials get almost completely depleted and the decrease of the fuel-to-moderator ratio favors the rise of the thermal neutron peak and accordingly the increase of the cross sections of fissile materials. Fertile elements show an opposite trend as expected.

From the relative differences between the two cases at different temperatures $(900 \mathrm{~K}$ and $1200 \mathrm{~K}$ ) it is possible to conclude that a simple parametrization of the cross sections along the burnup and across different pebble temperatures can be obtained with a linear interpolation between the three relevant burnup states of 0,30 and $90 \mathrm{MWd} / \mathrm{kgU}$.

Despite the link between the spectrum and the cross section value, the self-shielding effect seen for a single pebble in an infinite lattice is weaker if the same pebble is analyzed in a real core configuration, where pebbles with different burnup are randomly mixed. Considering the full core, pebbles share an average neutron spectrum given by the surroundings and thus the cross sections needed to perform the following burnup calculations must be obtained from core-level simulations. Nevertheless, the $5 \times 5 \times 5$ lattice of average pebbles with a fresh one in the center has been used to prove the weakening of the self-shielding effect in an equilibrium core configuration compared to the infinite lattice case. The one-group microscopic fission and capture cross section trends along the burnup for the modeled 5x5x5 cube are shown in Fig. 11. The linear evolution of cross sections along burnup in a core-like configuration suggests that the burnup matrices that will be generated at the core level (see Section 5) will follow a similar trend. However, the burnup matrices will be generated according to the same three burnup points $(0,30$ and $90 \mathrm{MWd} / \mathrm{kgU})$ observed for a single pebble depletion in an infinite lattice for the sake of a conservative parametrization. 

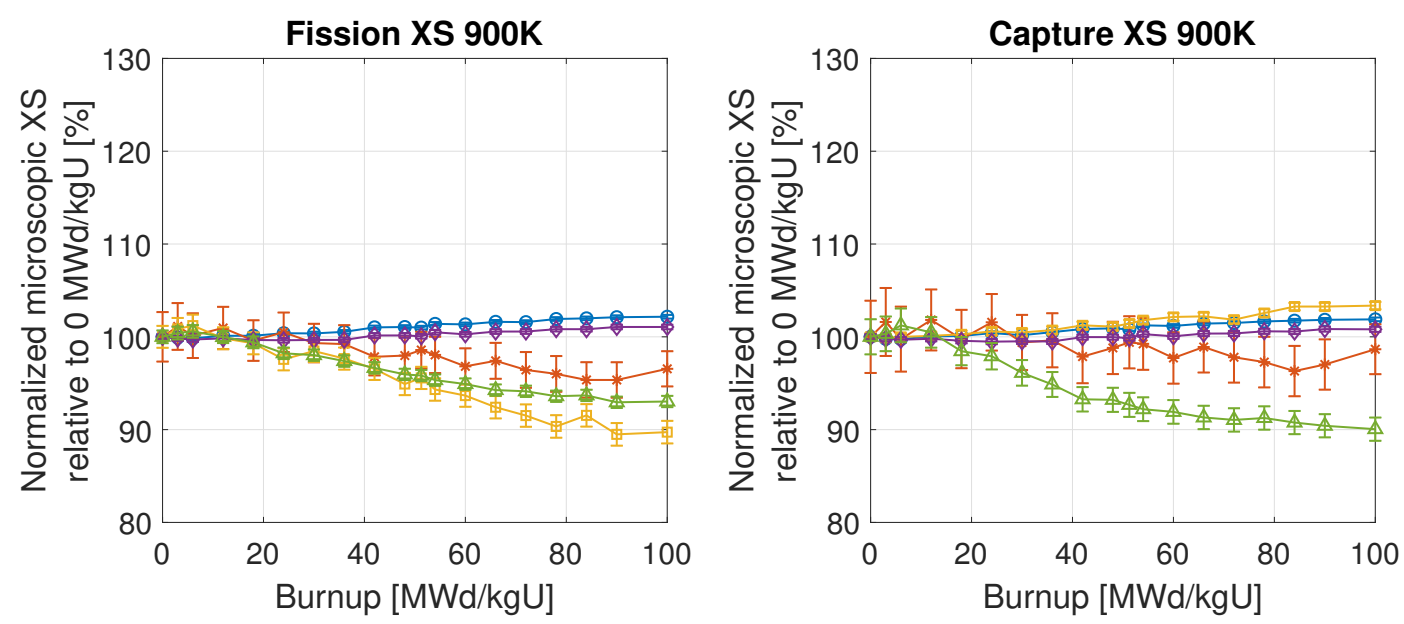

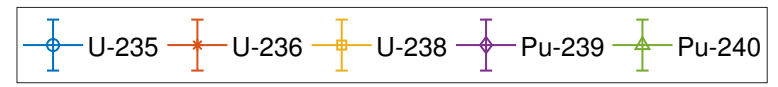

Fig. 11: Evolution of normalized one-group microscopic fission and capture XS of ${ }^{235} \mathrm{U},{ }^{236} \mathrm{U},{ }^{238} \mathrm{U},{ }^{239} \mathrm{Pu}$ and ${ }^{240} \mathrm{Pu}$ along the burnup (from 0 to $100 \mathrm{MWd} / \mathrm{kgU}$ ) for a single pebble in the center of a $5 \times 5 \times 5$ infinite square lattice of pebbles, all with average fuel composition. The pebble is burned at constant neutron flux and its temperature is $900 \mathrm{~K}$. Uncertainties are below $2.7 \%$.

\subsection{Sensitivity to the pebble temperature}

The perfect dispersion of tiny TRISO particles in a big volume of graphite legitimizes the assumption of a uniform temperature level of the fuel, the layers surrounding the fuel kernel and the graphite matrix. Lower and upper temperatures respect to the nominal $900 \mathrm{~K}$, namely $600 \mathrm{~K}$ and $1200 \mathrm{~K}$, have been chosen between the temperatures available in the ENDF/B-VII.0 cross sections data library [16] to study how temperature changes affect the cross sections of a single pebble in an infinite lattice.

Temperature variations can cause two immediate effects at the neutronics level: the resonance broadening and the shift of the Maxwellian neutron spectrum peak. In the long term, they can cause an additional cumulative effect through changes in the fuel composition. To separate immediate and cumulative effects, cross sections have been calculated first perturbing the temperature locally and then propagating the temperature variation along the burnup to take into account the fuel composition evolution. However, it has been proved that the cumulative effect has a low influence on the cross sections, since the differences between the two cases at $90 \mathrm{MWd} / \mathrm{kgU}$ are in the order of $2.3 \%$. Figure 12 shows the evolution of the one-group microscopic cross sections, normalized with respect to their value for the nominal temperature case (900 K), for ${ }^{235} \mathrm{U},{ }^{236} \mathrm{U},{ }^{238} \mathrm{U},{ }^{239} \mathrm{Pu}$ and ${ }^{240} \mathrm{Pu}$ at $90 \mathrm{MWd} / \mathrm{kgU}$ and constant flux. The two plots in Fig. 12 represent cross section variations for local perturbed temperature states of the fuel composition obtained from the full burnup at $900 \mathrm{~K}$. Error bars are not visible because they are in the order of $0.3 \%$ due to the high number of neutrons employed ( 2.5 million). The immediate temperature variations affect the one-group microscopic cross sections with differences up to $\pm 23 \%$ for both capture and fission of the main actinides. Figure 13 shows the normalized spectrum at $90 \mathrm{MWd} / \mathrm{kgU}$ for different burnup temperatures and the microscopic fission cross sections of ${ }^{235} \mathrm{U},{ }^{238} \mathrm{U}$ and ${ }^{239} \mathrm{Pu}$ as a function of incident neutron energy from the ENDF/BVII.0 library [16]. As the temperature increases, the thermal spectrum hardens and consequently crosses the first resonance peak of ${ }^{239} \mathrm{Pu}$ around $0.3 \mathrm{eV}$, which explains the increase of ${ }^{239} \mathrm{Pu}$ cross section with the pebble temperature. In the same way, the shift of the Maxwellian peak is responsible for the decrease of the ${ }^{235} \mathrm{U}$ cross section, whilst it does not affect the value of ${ }^{238} \mathrm{U}$ cross section, which is several orders of magnitude smaller than ${ }^{235} \mathrm{U}$ and ${ }^{239} \mathrm{Pu}$ cross sections. Therefore, the resonance broadening effect is negligible compared to the effect of the spectrum shift and no relevant dependencies on the temperature are visible for ${ }^{236} \mathrm{U},{ }^{238} \mathrm{U}$ and ${ }^{240} \mathrm{Pu}$. Capture cross sections have trends similar to fission cross sections.

\subsection{Sensitivity to the graphite proximity}

The full-core model of the HTR-PM in Serpent 2 is required to study the effect of the graphite reflector on one-group microscopic cross sections. The average fuel composition has been calculated based on the assumption of the 15-pass burnup evolution of a single pebble as previously discussed and it has been assigned to the 420,000 pebbles present in the core. In the defined average burnup environment, fission cross sections have been calculated with detectors in the axial (in the rotational symmetric axis) and radial (in the half-height) directions of the core.

Cross sections in Fig. 14a can be considered constant between 0 and $90 \mathrm{~cm}$ radius with a maximum error of $\pm 2 \%$, whereas between the radii of $90 \mathrm{~cm}$ and $150 \mathrm{~cm}$ they differ up to $\pm 34 \%$ from the core center. As for the axial direction 
Fission XS at $90 \mathrm{MWd} / \mathrm{kgU}$

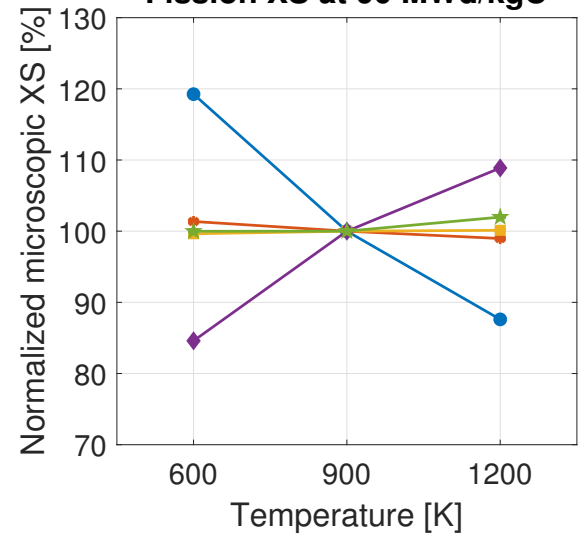

Capture XS at $90 \mathrm{MWd} / \mathrm{kgU}$

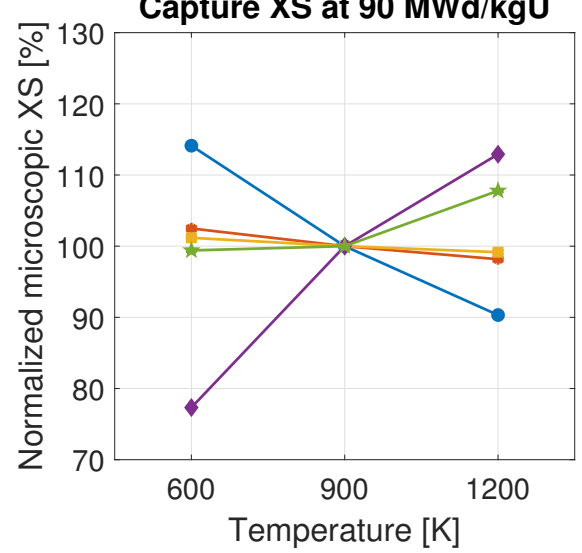

$\mathrm{I}-\mathrm{U}-235 \rightarrow \mathrm{I}-236 \rightarrow \mathrm{I}-\mathrm{U}-238 \rightarrow \mathrm{Pu}-239 \rightarrow \mathrm{I} \mathrm{Pu}-240$

Fig. 12: Temperature sensitivity at $600 \mathrm{~K}$ and $1200 \mathrm{~K}$ (with respect to the nominal temperature of $900 \mathrm{~K}$ ) for one-group microscopic fission and capture XS for ${ }^{235} \mathrm{U},{ }^{236} \mathrm{U},{ }^{238} \mathrm{U},{ }^{239} \mathrm{Pu}$ and ${ }^{240} \mathrm{Pu}$ at $90 \mathrm{MWd} / \mathrm{kgU}$ and nominal neutron flux. Temperature perturbations are local. Error bars are not visible because uncertainties are below $0.3 \%$.

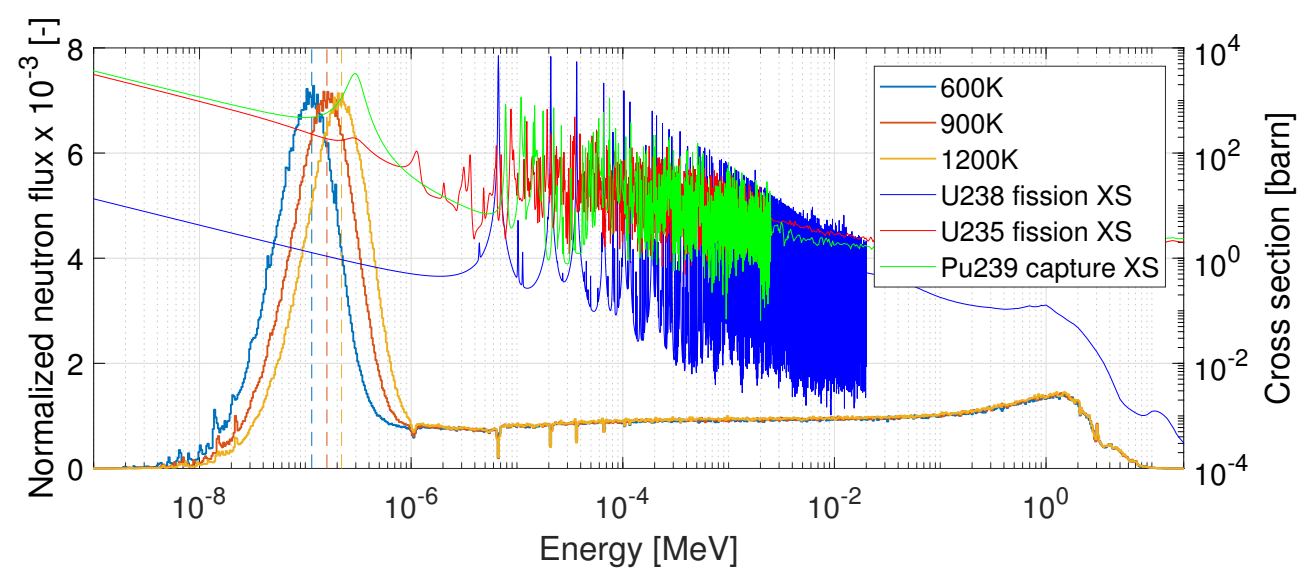

Fig. 13: Normalized neutron spectrum of a single pebble at $90 \mathrm{MWd} / \mathrm{kgU}$ at different fuel and moderator temperatures, alongside with microscopic fission XS of ${ }^{235} \mathrm{U}$ and ${ }^{239} \mathrm{Pu}$ and capture XS of ${ }^{238} \mathrm{U}$, as a function of incident neutron energy from the ENDF/B-VII.0 library [16]. Spectrum uncertainties are below $2 \%$.

shown in Fig. 14b, variations up to $\pm 50 \%$ are found near the cone section (at the core bottom) within $60 \mathrm{~cm}$ from the core outlet. The fission cross section variation within a range of $60 \mathrm{~cm}$ from the graphite reflector is consistent with the diffusion length typical of graphite-moderated systems equal to roughly $60 \mathrm{~cm}$. A higher share of thermal neutrons slowed down in the graphite reflector increases the thermal peak of the spectrum. Therefore, microscopic cross sections of fissile elements rise while the ones of fertile elements fall, as with the variations along the burnup. For the sake of simplicity, the evolution of cross sections due to the graphite proximity is approximated by a linear trend in a range of $60 \mathrm{~cm}$ from graphite.

\section{Cross sections parametrization at core-level}

Based on the knowledge acquired from the sensitivity studies, one-group microscopic cross sections of a single pebble in an infinite square lattice are affected by the burnup state, the pebble temperature, and the graphite proximity. However, as previously proven, spectral effects are milder in a real core geometry where pebbles with different burnup are neighbors and all share the same neutron spectrum. Therefore, the set of cross sections necessary to solve the Bateman equations needs to be generated and parametrized with full-core Serpent 2 calculations.

Two different sets of cross sections under the form of burnup matrices were generated for six pebbles surrounded by an average fuel composition in the core: one set when the six pebbles are placed in the bulk of the core and the other when they are positioned in the region close to the graphite reflector (see Fig. 15). Although the minimal perturbation to the average fuel composition corresponds to the substitution of only one pebble with a not-average burnup, the choice of generating 
(a)

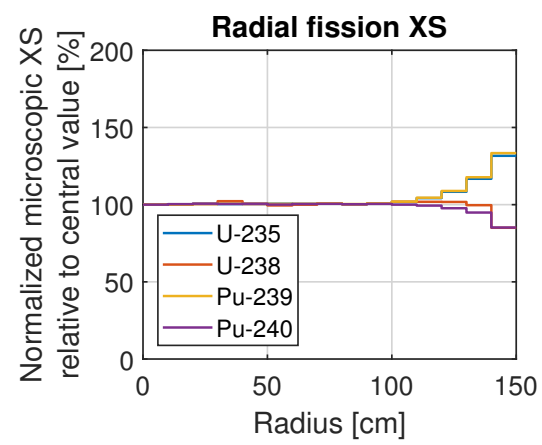

(b)

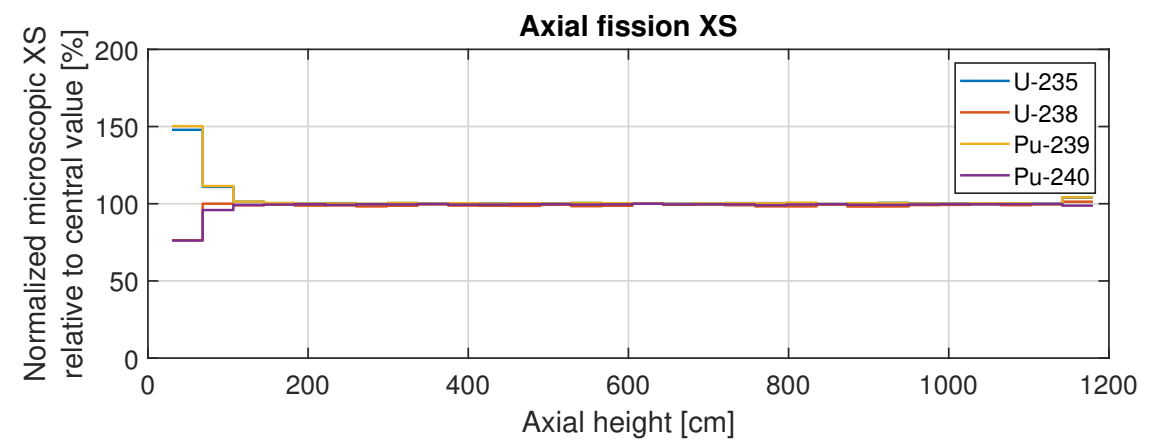

Fig. 14: Radial and axial parametrization of one-group microscopic fission XS of ${ }^{235} \mathrm{U},{ }^{238} \mathrm{U},{ }^{239} \mathrm{Pu}$ and ${ }^{240} \mathrm{Pu}$ for the $\mathrm{HTR}$ PM core with average fuel composition. Error bars, which are not shown in the plots, are within $10 \%$.

cross sections for six neighboring pebbles instead of one derives from the fact that the small fuel volume contained in a single pebble implies high statistical errors in Monte Carlo simulations. The error on the cross sections contained in the burnup matrices has been estimated to be approximately within $10 \%$, knowing that the error on the neutron flux is around $6 \%$ for a Serpent 2 simulation employing 10 million neutrons. Nevertheless, it has been demonstrated that the cross section values calculated for a single pebble in infinite lattice are within the range of uncertainty of the burnup matrices generated for six pebbles. For each of the two sets, burnup matrices have been created for three different burnup states (0, 30 and 90 $\mathrm{MWd} / \mathrm{kgU})$ and three different pebble temperatures $(600,900$ and $1200 \mathrm{~K})$. The Monte Carlo simulations output consists in two sets of nine well-known burnup matrices with fixed dimensions. The matrices must be normalized to be flux-independent (with the flux profile calculated for the average full-core) and decay-free.
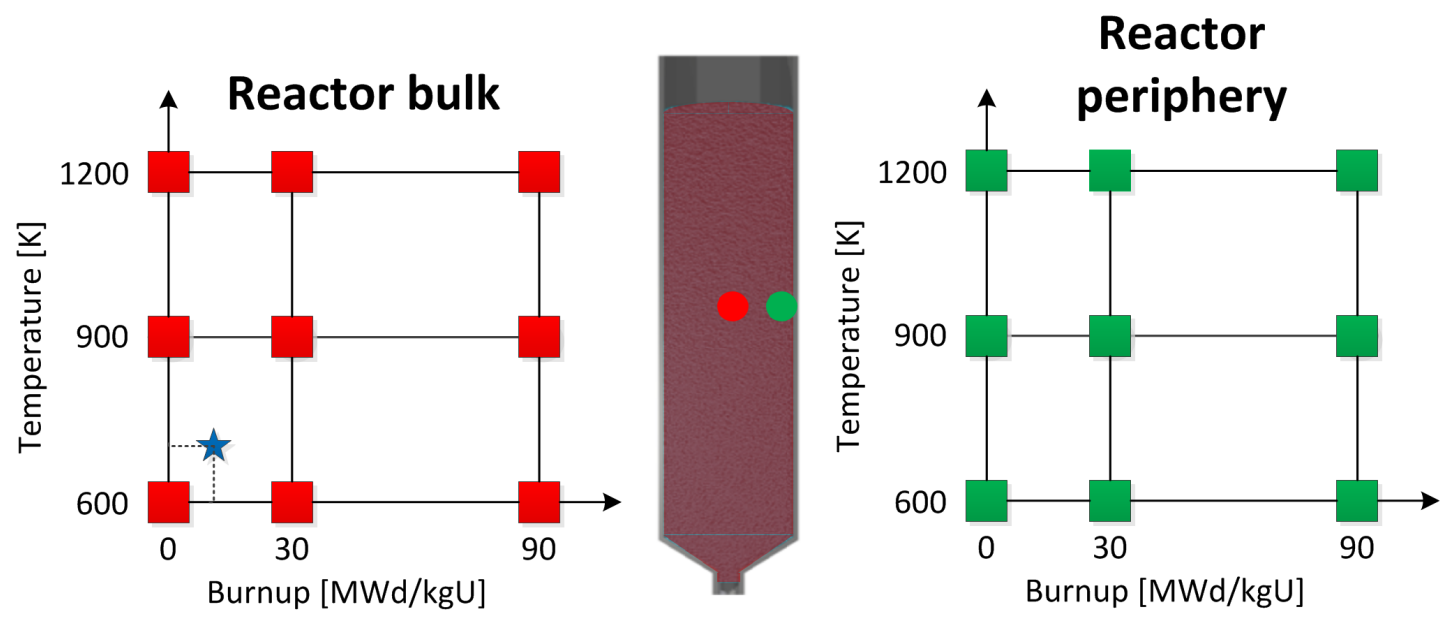

Fig. 15: Two sets of nine BU flux-independent and decay-free matrices each (represented by the squares): one for pebbles in the reactor bulk (left) and one for pebbles close to the graphite reflector (right). The star is an example of a pebble state that needs to be interpolated.

The normalized matrices need to be interpolated according to the burnup state and the temperature (as a function of the position) of the single pebble moving throughout the HTR-PM core. The interpolation between the matrices of interest is performed with a quadratic interpolation in Matlab, which is visualized in Fig. 16. The burnup matrices of the set generated for the reactor bulk are interpolated by default, as if the pebble would always flow in the center of the core (between 0 and $90 \mathrm{~cm}$ radius). In case the pebble is actually moving downwards in the reactor periphery (between 90 and $150 \mathrm{~cm}$ radius) an additional interpolation is done between the burnup matrices belonging to the periphery set. Afterwards, the two resulting interpolated matrices, one for the center and one for the outer zone, need an additional linear interpolation to obtain the final burnup matrix, necessary for the solution of the Bateman equations. 


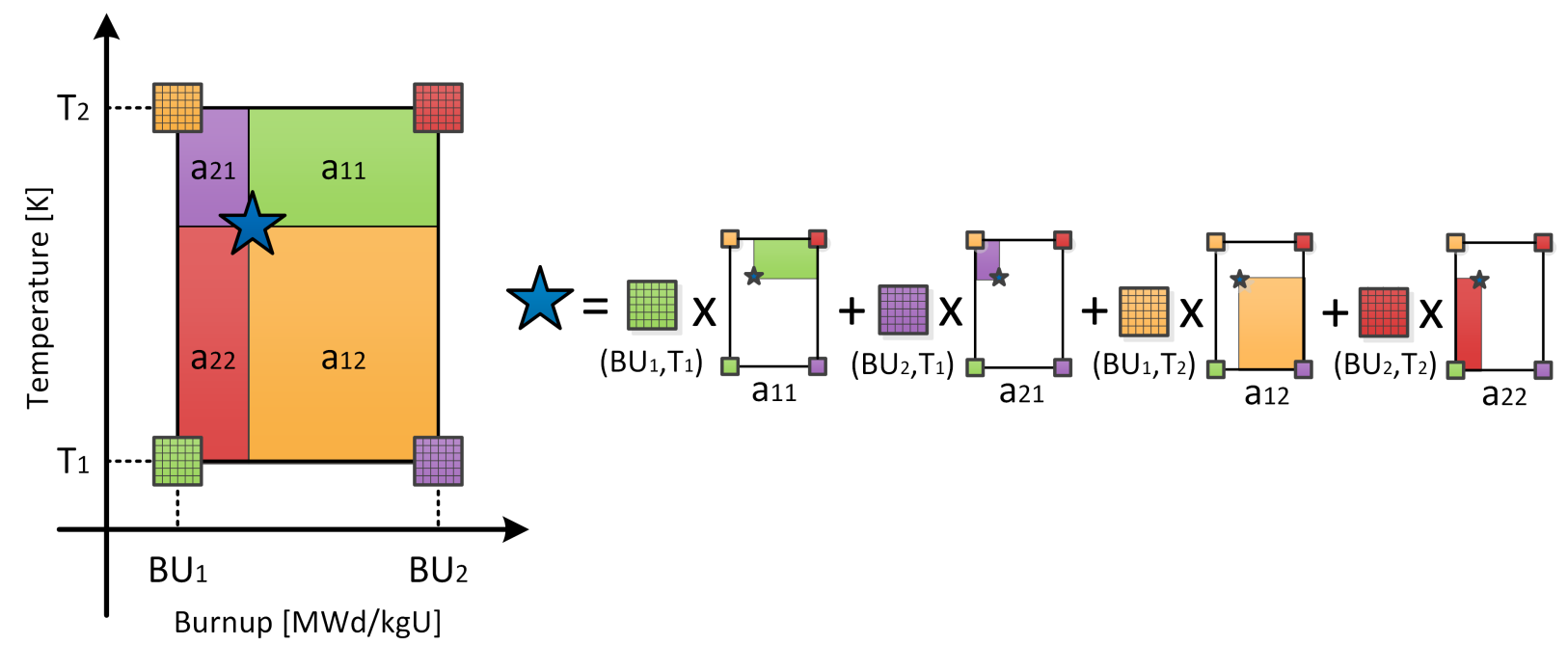

Fig. 16: Visual representation of the quadratic method used for the burnup matrices interpolation. The star represents the pebble state for which the matrices are interpolated.

\section{Coupling of pebble movement and burnup: the MPB script}

The MPB (Moving Pebble Burnup) script is a Matlab-based burnup script developed to perform the full-history burnup, namely from fresh to the maximum allowed burnup, of single HTR-PM pebble during its multiple passes through the reactor core. The goal is to loosely couple the pebble movement with the neutronics solver in order to perform statistical evaluations that give insights into the burnup process of the HTR-PM reactor.

The MPB script loosely couples:

- The eleven selected pebble trajectories (see Fig. 2) obtained by DEM calculations.

- The parametrized burnup matrices generated with full-core Monte Carlo calculations (see Fig. 15).

- The fixed neutron flux obtained with average fuel composition and average fuel temperature in a full-core Monte Carlo calculation (see Fig. 17a).

- The temperature profile in the core reconstructed from literature [18] (see Fig. 17b).

- The randomness of the pebble insertion (see Fig. 3b) and the variable number of passes through the core for each pebble.

\subsection{MPB script structure and modules}

The MPB procedure is thoroughly presented in Fig. 18 and explained hereafter. At the beginning, the pebble is initialized with the fresh fuel composition and then a random generator chooses a trajectory according to the probability distribution function previously defined (see Fig. 3b). The choice of one trajectory implies the definition of pebble positions, burnup timesteps, neutron flux levels and temperatures along the path where many micro burnup steps are performed. When the pebble moves to its first position within a certain timestep, a neutron flux and a temperature are associated with the position in hand. The burnup matrices obtained with Serpent 2 and containing the normalized one-group cross sections are interpolated according to the achieved burnup, the temperature at that position and the graphite proximity, as explained in Section 5. The resulting interpolated matrix is renormalized by being multiplied by the local neutron flux (in Fig. 17a) and then it is extended with the decay terms. The matrix form of the burnup equation is solved with the CRAM method [19] and a vector with the new fuel composition is obtained as an output. The achieved burnup is calculated from the isotopic composition in terms of \%FIMA and it is converted in MWd/kgU. The described procedure is repeated for each of the micro burnup steps, normally being between 9 and 15 depending on the speed of the pebble along the trajectory (see Tab. 2). Once the pebble reaches the core bottom, the final burnup achieved is set as the initial burnup at the beginning of the consecutive pass and this mechanism is repeated until the burnup exceeds the target burnup of $90 \mathrm{MWd} / \mathrm{kgU}$, used as control logic. Therefore, the number of passes to reach $90 \mathrm{MWd} / \mathrm{kgU}$ may vary according to the randomly chosen path of the single pebble. This randomness allows to obtain fully independent pebble burnup histories. Hence, thousands of independent pebble histories can be generated with multiple runs of the MPB script and a statistical approach can be used to investigate some important characteristics, such as the archived burnup distribution at each pass or the distribution of the number of passes necessary to reach a certain threshold, namely the target burnup of $90 \mathrm{MWd} / \mathrm{kgU}$. In the current work, 3,000 single pebble histories have been simulated with the MPB script. The results are presented in the following section. 
(a)

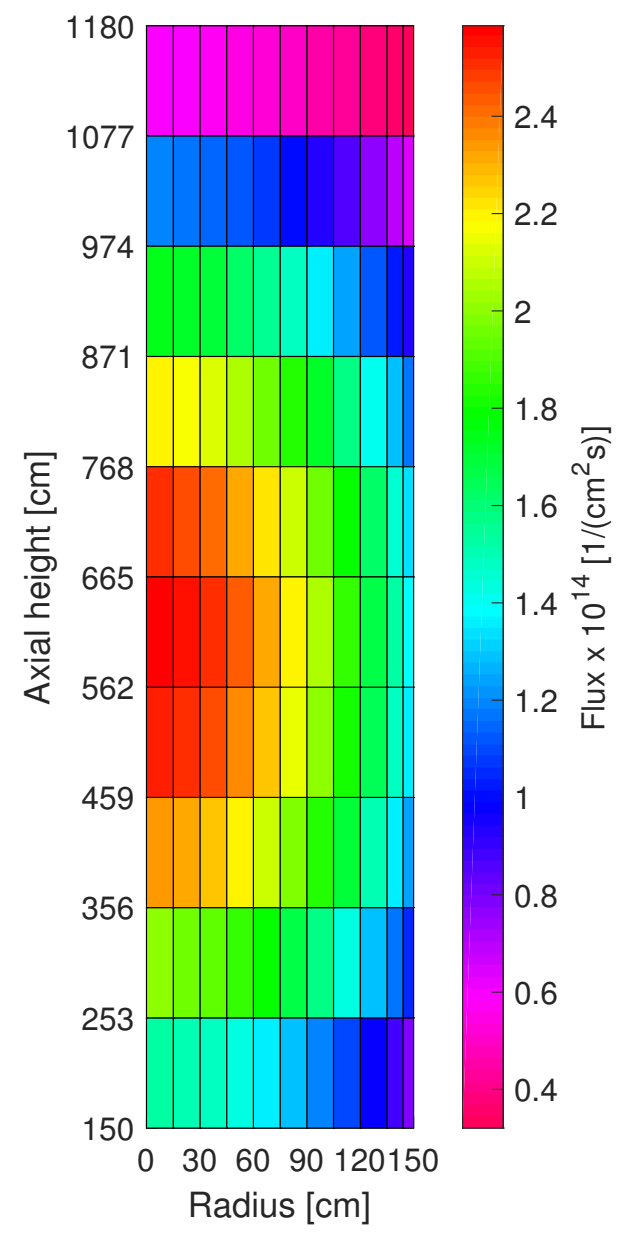

(b)

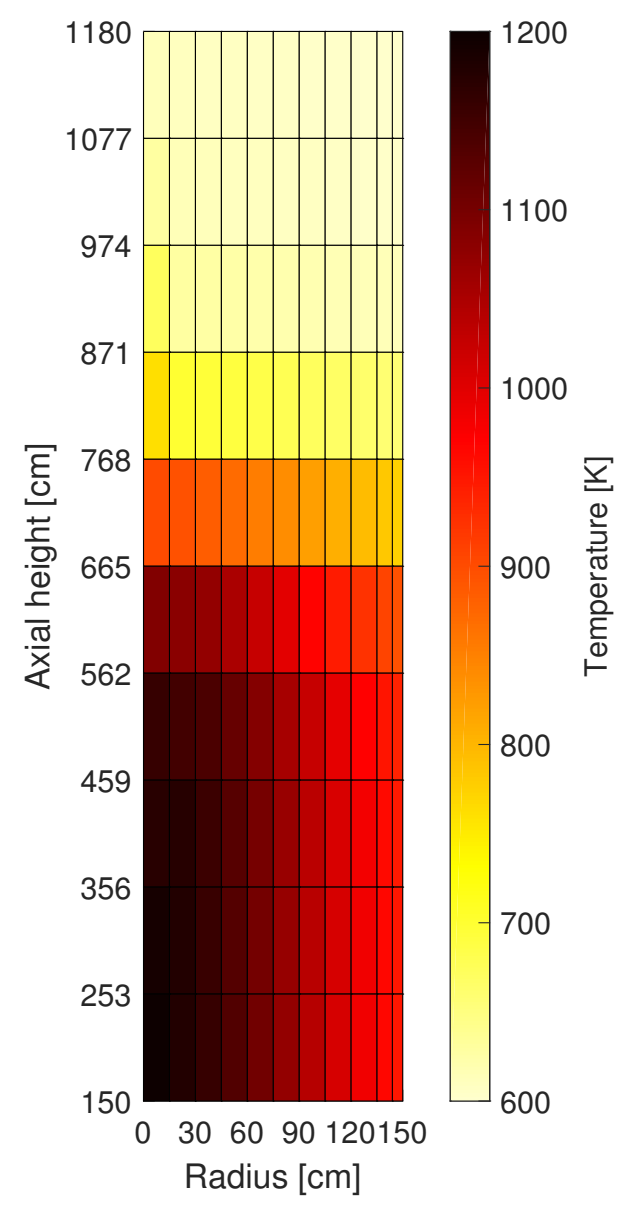

Fig. 17: (a) Local neutron flux map in the half cut along axial direction of the HTR-PM core obtained with average fuel composition and constant fuel temperature with Serpent 2. (b) Local fuel temperature map in the half cut along axial direction of the HTR-PM core, reconstructed from data taken in the literature [18].

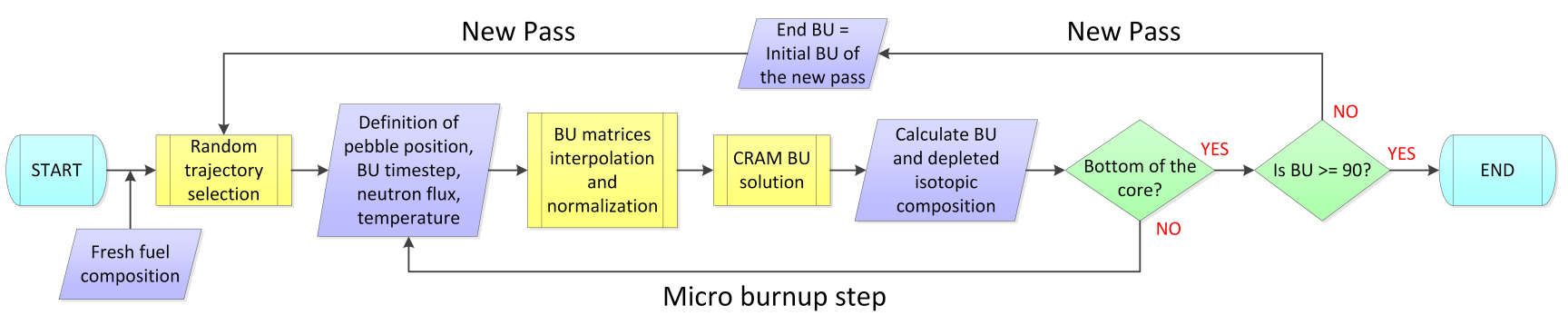

Fig. 18: Flowchart of the MPB script.

\section{Statistic evaluations on 3,000 pebble histories simulated with the MPB script}

Each MPB output file contains one of the 3,000 simulated and fully independent pebble histories. The script records the randomly chosen concentric zone where the pebble flows, the initial and the final burnup and the pebble residence time for every pass through the HTR-PM core.

\subsection{Statistical burnup distributions}

From the 3,000 pebble histories simulated with the MPB script is possible to derive statistical distributions. For instance, considering $90 \mathrm{MWd} / \mathrm{kgU}$ as the threshold to discharge a burned pebble and to quit the script, it is possible to conclude that in general pebbles are discharged after a number of passes that varies between 15 and 17, as shown in Fig. 19a. 56\% of the 
total 3,000 pebbles is discharged at the $16^{\text {th }}$ pass, while $38 \%$ at the $17^{\text {th }}$ pass and only $6 \%$ at the $15^{\text {th }}$ pass. Therefore, after the $15^{\text {th }}$ pass $6 \%$ of the pebbles are discharged and the remaining $94 \%$ enters the reactor for the $16^{\text {th }}$ time. In the same way, after pass number 16 only the $36 \%$ of the 3,000 original pebbles are recirculated, while after pass number 17 all of them will be discharged, as shown in Fig. 19b.

(a)

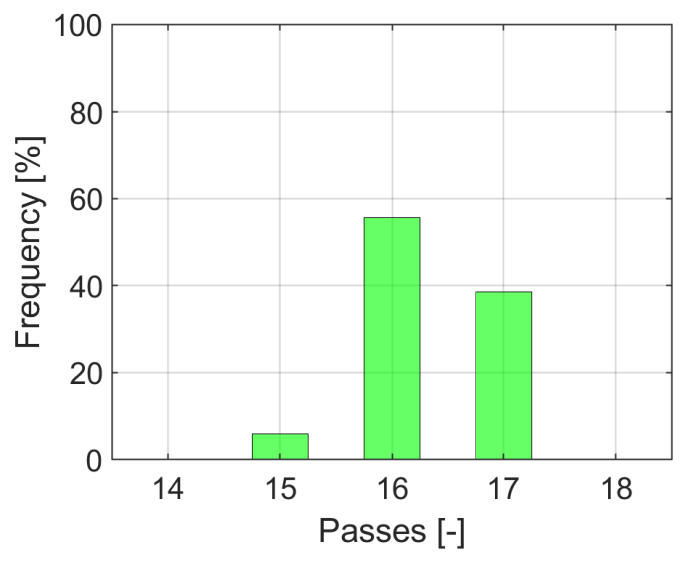

(b)

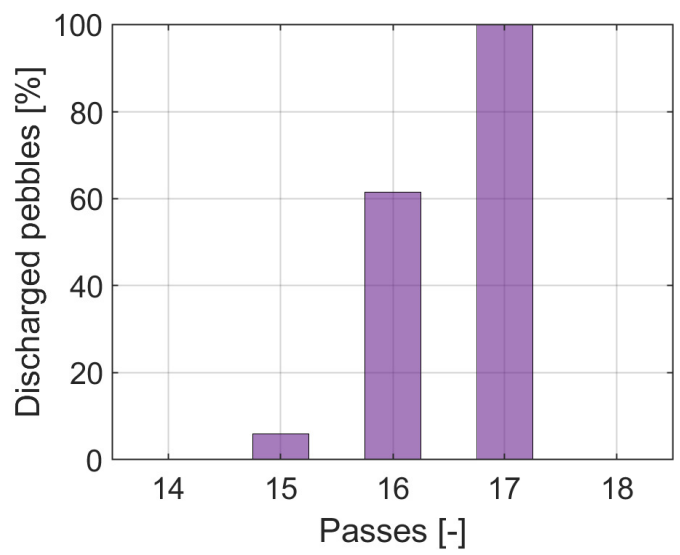

Fig. 19: (a) Relative frequency histogram of the number of passes necessary to reach the average discharge burnup of 90 MWd/kgU. (b) Histogram of the share of pebbles discharged after each pass in the HTR-PM core over 3'000 histories.

A statistical distribution of the burnup can be obtained for each of the 17 passes that a pebble may experience. Fig. 20 shows the statistical distributions of burnup at each pass with their mean value. The distributions are normalized by 3,000 so that the area under each curve is proportional to the number of pebbles in the core. The distribution at pass number 1 shows high frequencies in a small number of bins (of width $0.5 \mathrm{MWd} / \mathrm{kgU}$ ) because the fixed burnup starting point at $0 \mathrm{MWd} / \mathrm{kgU}$ implies that the burnup achieved at the core outlet is also fixed and depends only on the reactor concentric zone randomly chosen. In addition, observing carefully the same distribution, it is possible to see a dip that corresponds to a jump between the fixed values of the achieved burnup after the first pass.

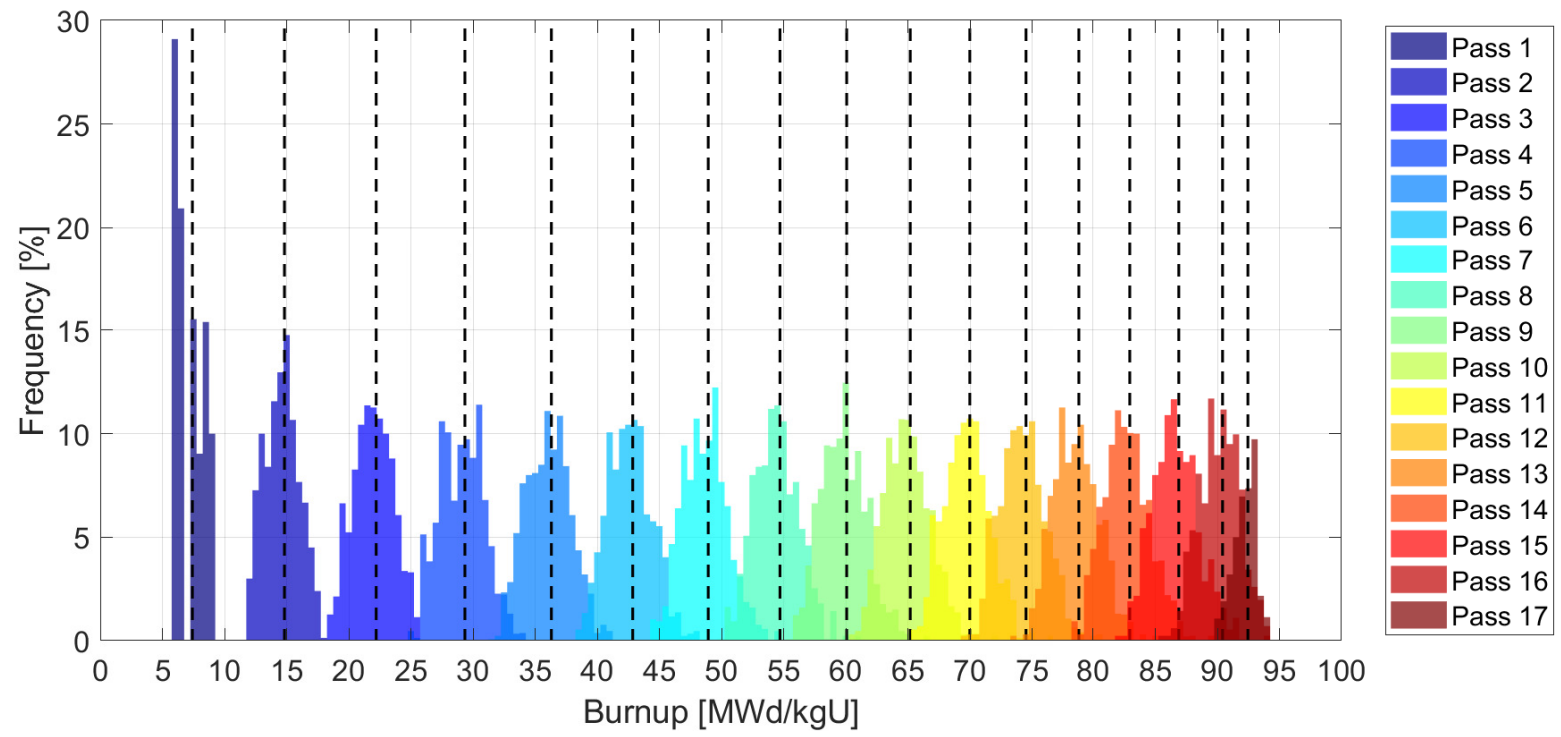

Fig. 20: Statistical distributions of burnup at each pass through the reactor core, in terms of relative frequency. The distributions are normalized by 3,000 so that the area under each curve is proportional to number of pebble present (not already discharged) in the core. 


\subsection{Self-compensation effect}

As shown in Fig. 20, the average values of the distributions get closer with the burnup progression because, as proved by Fig. 21, the average burnup gained per pass decreases according to the decrease of the fission reaction rate due to the fuel depletion. A fully burned pebble gains a burnup roughly 50\% lower than what a fresh pebble would gain. As a consequence, a miss-handling of a burned fuel element that is recirculated more than prescribed is unlikely to lead to an exceedance of the maximum allowed burnup of $100 \mathrm{MWd} / \mathrm{kgU}$.

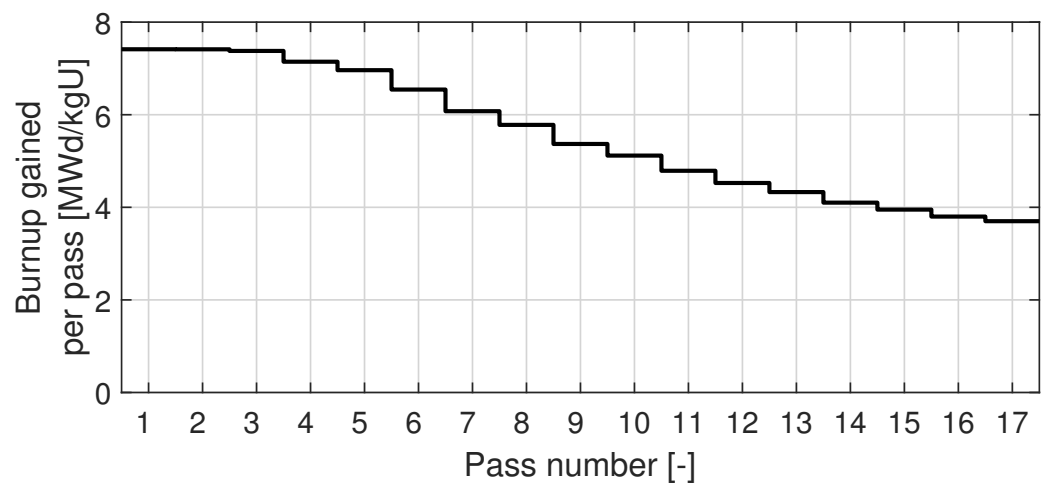

Fig. 21: Average burnup of a single pebble gained per pass.

Furthermore, it has been proved that the core shows a self-compensation effect, meaning that it compensates burnup under- and over-runs in the successive passes. The compensation is ensured by the constant flux level seen by each pebble, since a single pebble is not able to influence the equilibrium properties of the HTR-PM core, combined with the excess or lack of fissile material. This effect is relevant because of the high number of passes through the reactor core. As a matter of fact, it has been observed that the pebble histories do not significantly differ between each other despite the randomness of the pebble reinsertion.

\subsection{New estimate of the average fuel composition}

In the present work, the average fuel composition employed for the computation of neutron flux maps (see Fig. 17a) was calculated assuming 15 equal burnup steps of $6 \mathrm{MWd} / \mathrm{kgU}$ during the depletion process, as explained in Section 3.2 and Fig. 5. However, Fig. 20 and 21 prove that the employed assumptions were not accurate since the average number of passes in the HTR-PM was estimated to be 16 and the burnup gained in successive passes progressively decreases. Hence, the average fuel composition and all the estimates bases on it must be recalculated.

From the results of the 3,000 pebble histories generated with the MPB script it is possible to obtain a modified fuelloading scheme and to estimate a new average burnup level of $\sim 51 \mathrm{MWd} / \mathrm{kgU}$, corresponding to an increase by $13 \%$ of the previous average burnup level. It has been estimated that the use of the new average composition implies an increment of the average neutron flux by roughly $3 \%$ and thus a speed-up of the burnup process, while the burnup matrices are insensitive to flux variations, as demonstrated in Section 4.1. As a consequence, the discharge burnup will be achieved in a smaller number of passes, as proven by Fig. 22a and Fig. 22b. According to the first guess on the HTR-PM fuel loading scheme, no pebbles were discharged after pass 14 , while with the new scheme $1.4 \%$ of the pebbles reach $90 \mathrm{MWd} / \mathrm{kgU}$ already at the end of the $14^{\text {th }}$ pass. The number of pebbles discharged increases from $6 \%$ to $37 \%$ after pass 15 and from $56 \%$ to $60 \%$ after pass 16 . Accordingly, very few pebbles circulate in the core for a $17^{\text {th }}$ time.

The statistical distribution calculated in this section should be updated according to the new background composition, which must be calculated iterating between the average fuel composition, the HTR-PM neutron flux and the MPB script until convergence is reached. An additional refinement to the model and to the calculation of the best estimate average composition would be the division of the full-core in axial and radial zones, each characterized by its own average value of the fuel composition.

\subsection{Correlation of ${ }^{137} \mathrm{Cs}$ content and burnup}

As of today, no detailed description of the machine that discharges the fuel pebbles has been released. This machine must check the burnup of every pebble exiting the core and test if their integrity has been preserved. It is reasonable to suppose that a practical method to check the pebble burnup is the gamma detection of ${ }^{137} \mathrm{Cs}$. ${ }^{137} \mathrm{Cs}$ decays to the metastable ${ }^{137 \mathrm{~m}} \mathrm{Ba}$ by $\beta^{-}$emission, then the ${ }^{137 \mathrm{~m}} \mathrm{Ba}$ reaches the ground state emitting a gamma ray of $662 \mathrm{keV}$ with a half-life of 2.6 minutes. The gamma ray emitted by ${ }^{137} \mathrm{Ba}$ can be easily detected by sodium iodine (NaI) scintillator detectors or high-purity 
(a)

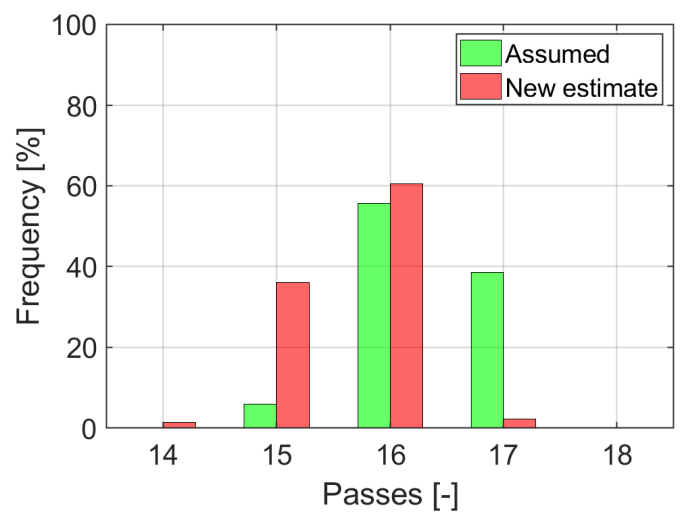

(b)

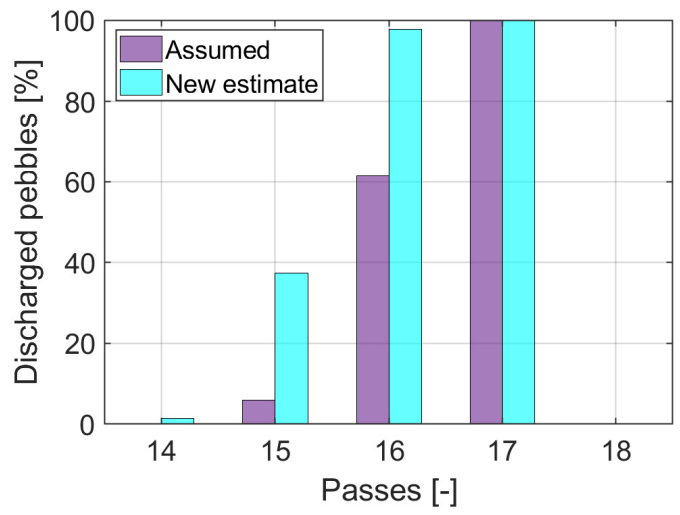

Fig. 22: (a) Relative frequency histogram of the number of passes necessary to reach the average discharge burnup of $90 \mathrm{MWd} / \mathrm{kgU}$ for the first estimate fuel average composition and for the new estimated value. (b) Histogram of the share of pebbles discharged after each pass in the HTR-PM core over 3000 histories using the assumed fuel loading scheme and the updated one.

germanium detectors, both properly calibrated. The obtained spectrum will show a photoelectric peak at the energy of 662 $\mathrm{keV}$ with a peak height proportional to the number of ${ }^{137} \mathrm{Cs}$ atoms that decayed in the fuel (namely the pebble activity). Hence, it is possible to correlate the number of ${ }^{137} \mathrm{Cs}$ atoms present in a burned pebble with its burnup, as shown in Fig. 23a where the cesium content increases linearly with burnup, being a fission product. Figure 23b presents only the last part of the curve, where the ${ }^{137} \mathrm{Cs}$ content at $90 \mathrm{MWd} / \mathrm{kgU}$ corresponds on average to $1.282 \times 10^{20}$ atoms of cesium. Using this value as a threshold to determine when a pebble reaches the discharge burnup, it is possible to count the number of pebble histories among the 3,000 calculated that show a cesium content below the threshold after the last pass through the reactor core (which might be the $14^{\text {th }}, 15^{\text {th }}, 16^{\text {th }}$ or $17^{\text {th }}$, as shown in Fig. 22a). Out of 3,000 independent histories only $2.9 \%$ of them are still presenting a cesium content below the threshold after the final pass decided on the basis of the criteria $\mathrm{BU}_{\text {end }}>90 \mathrm{MWd} / \mathrm{kgU}$. Therefore, the gamma measurement of ${ }^{137} \mathrm{Cs}$ is an effective method for the pebble burnup check at the core outlet pipe.

(a)

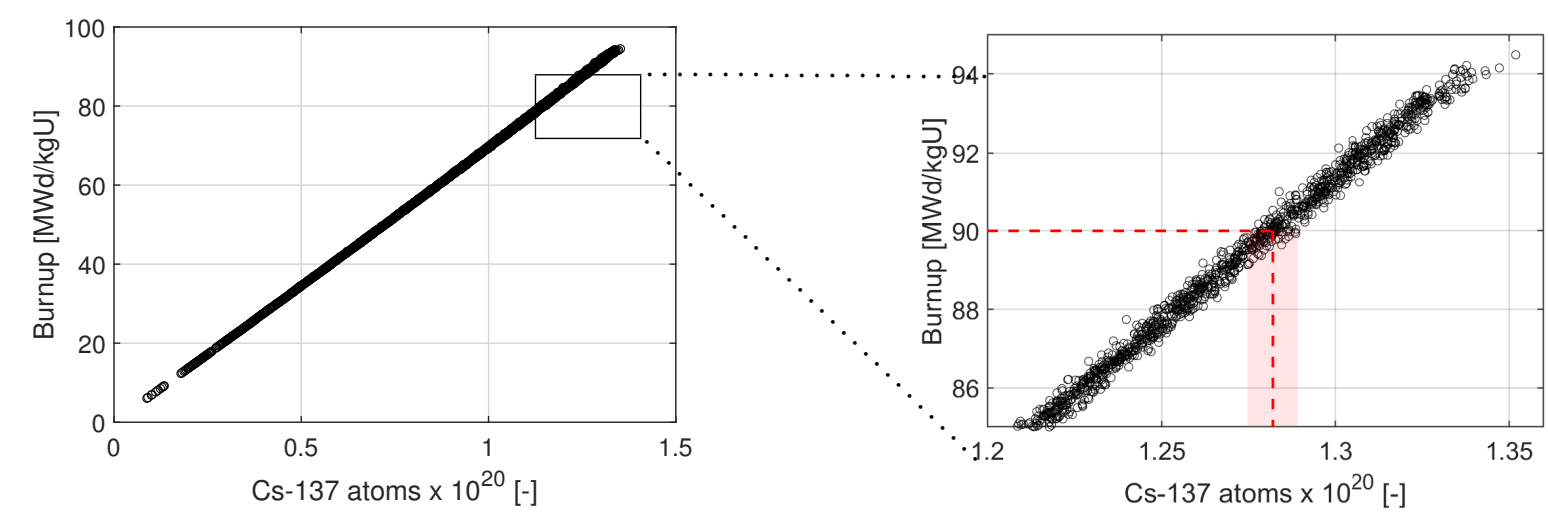

Fig. 23: (a) Evolution of the number of ${ }^{137} \mathrm{Cs}$ atoms along the burnup. (b) The threshold value for ${ }^{137} \mathrm{Cs}$ atom is found in a magnification of the same plot.

\section{Conclusions}

The aim of this work was to loosely couple the pebble movement in the HTR-PM reactor with the neutronics solver through cross section parametrization at the core level. The MPB dedicated burnup script has been developed to simulate single pebble histories in order to draw statistical conclusions on the multi-pass fuel loading scheme of the HTR-PM. 
In the first part of the work, DEM simulations were carried out to simulate the full pebble movement in the HTR-PM reactor. From the simulation results, eleven pebble trajectories were sampled as representative of the pebble movement in the same number of concentric zones of the reactor core.

From the neutronics sensitivity studies on cell-level and core-level, it has been concluded that one-group microscopic cross sections are affected by the burnup level, the pebble temperature, and the graphite proximity. However, the spectral changes responsible for these effects are weaker in the full HTR-PM core due to the smeared neutron spectrum in an equilibrium core. Hence, the generation and parametrization of one-group microscopic cross sections (under the form of burnup matrices) for the solution of the Bateman equation has been performed for the HTR-PM full-core geometry filled with pebbles with an average fuel composition.

The sampled pebble trajectories and the sets of parametrized burnup matrices were loosely coupled together in the MPB script, along with the core flux level and the temperature profile. By simulating 3,000 independent pebble histories, it was possible to conclude that the average number of passes needed for a single pebble to reach $90 \mathrm{MWd} / \mathrm{kgU}$ is equal to 16 . Furthermore, the average burnup gained per pass decreases and the core shows a self-compensation effect. It has also been pointed out the need for an iteration process between the computed average fuel composition, the HTR-PM neutron flux and the MPB script in order to obtain the best estimate average fuel composition. In addition, the gamma spectroscopy of ${ }^{137} \mathrm{Cs}$ has been selected as a practical method to measure the burnup of the pebbles exiting the core.

The final conclusion is that the fuel cycle and the multi-pass fuel loading scheme of the HTR-PM are well-designed and feasible.

\section{Acknowledgements}

This work was accomplished within the Swiss Electricity Producers and ETH Zurich financed project: Feasibility and plausibility of innovative reactor concepts in a European electricity supply environment.

\section{References}

[1] Nickel, H., Nabielek, H., Pott, G., and Mehner, A., 2002. "Long time experience with the development of htr fuel elements in germany". Nuclear Engineering and Design, 217, 08, pp. 141-151.

[2] Zhang, Z., Dong, Y., Li, F., Zhang, Z., Wang, H., Huang, X., Li, H., Liu, B., Wu, X., Wang, H., Diao, X., Zhang, H., and Wang, J., 2016. "The Shandong Shidao Bay 200 MWe High-Temperature Gas-Cooled Reactor Pebble-Bed Module (HTR-PM) Demonstration Power Plant: An Engineering and Technological Innovation”. Engineering, 2(1), mar, pp. 112-118.

[3] Krepel, J., and Losa, E., 2019. "Closed u-pu and th-u cycle in sixteen selected reactors: Comparison of major equilibrium features". Annals of Nuclear Energy, 128, pp. $341-357$.

[4] Zhang, Z., Wu, Z., Wang, D., Xu, Y., Sun, Y., Li, F., and Dong, Y., 2009. "Current status and technical description of Chinese 2 x 250 MWth HTR-PM demonstration plant". Nuclear Engineering and Design, 239(7), jul, pp. 1212-1219.

[5] Teuchert, E., Hansen, U., and Haas, K., 1980. V.S.O.P.- computer code system for reactor physics and fuel cycle simulation. Tech. rep., Kernforschungsanlage Juelich G.m.b.H. (Germany, F.R.). Inst. fuer Reaktorentwicklung.

[6] Terry, W., Gougar, H., and Ougouag, A., 2002. "Direct deterministic method for neutronics analysis and computation of asymptotic burnup distribution in a recirculating pebble-bed reactor". Annals of Nuclear Energy, 29(11), jul, pp. $1345-1364$.

[7] Setiadipura, T., and Obara, T., 2014. "Development of Monte Carlo-based pebble bed reactor fuel management code". Annals of Nuclear Energy, 71, sep, pp. 313-321.

[8] Reitsma, F., 2004. "The pebble bed modular reactor layout and neutronics design of the equilibrium cycle". In PHYSOR 2004 -The Physics of Fuel Cycles and Advanced Nuclear Systems: Global Developments, Chicago, Illinois.

[9] Cogliati, J. J., and Ougouag, A. M., 2006. "Pebbles: A Computer Code for Modeling Packing, Flow, and Re- Circulation of Pebbles in a Pebble Bed Reactor". In 3rd International Topical Meeting on High Temperature Reactor Technology, Johannesburg, South Africa.

[10] Rycroft, C. H., Dehbi, A., Lind, T., and Güntay, S., 2013. "Granular flow in pebble-bed nuclear reactors: Scaling, dust generation, and stress". Nuclear Engineering and Design, 265, dec, pp. 69-84.

[11] Cundall, P. A., and Strack, O. D. L., 1979. "A discrete numerical model for granular assemblies". Gotechnique, 29(1), pp. 47-65.

[12] Kadak, A. C., and Bazant, M. Z., 2004. "Pebble flow experiments for pebble-bed reactors". In Proceedings of the Second International Topical Meeting on High Temperature Reactor Technology, Beijing, China.

[13] Yu, X., and Yu, S., 2010. "Analysis of fuel element matrix graphite corrosion in htr-pm for normal operating conditions". Nuclear Engineering and Design, 240(4), pp. 738 - 743.

[14] Zheng, Y., Shi, L., and Dong, Y., 2009. "Thermohydraulic transient studies of the Chinese 200 MWe HTR-PM for loss of forced cooling accidents". Annals of Nuclear Energy, 36(6), jun, pp. 742-751. 
[15] Leppänen, J., Pusa, M., Viitanen, T., Valtavirta, V., and Kaltiaisenaho, T., 2015. "The Serpent Monte Carlo code: Status, development and applications in 2013". Annals of Nuclear Energy, 82, aug, pp. 142-150.

[16] Chadwick, M., Herman, M., Obložinský, P., Dunn, M., Danon, Y., Kahler, A., Smith, D., Pritychenko, B., Arbanas, G., Arcilla, R., Brewer, R., Brown, D., Capote, R., Carlson, A., Cho, Y., Derrien, H., Guber, K., Hale, G., Hoblit, S., Holloway, S., Johnson, T., Kawano, T., Kiedrowski, B., Kim, H., Kunieda, S., Larson, N., Leal, L., Lestone, J., Little, R., McCutchan, E., MacFarlane, R., MacInnes, M., Mattoon, C., McKnight, R., Mughabghab, S., Nobre, G., Palmiotti, G., Palumbo, A., Pigni, M., Pronyaev, V., Sayer, R., Sonzogni, A., Summers, N., Talou, P., Thompson, I., Trkov, A., Vogt, R., van der Marck, S., Wallner, A., White, M., Wiarda, D., and Young, P., 2011. "ENDF/B-VII.1 Nuclear Data for Science and Technology: Cross Sections, Covariances, Fission Product Yields and Decay Data". Nuclear Data Sheets, 112(12), dec, pp. 2887-2996.

[17] Tang, C., Tang, Y., Zhu, J., Zou, Y., Li, J., and Ni, X., 2002. "Design and manufacture of the fuel element for the 10 MW high temperature gas-cooled reactor". Nuclear Engineering and Design, 218(1-3), oct, pp. 91-102.

[18] Suikkanen, H., Rintala, V., and Hyvärinen, J., 2017. "DEM in Analyses of Nuclear Pebble Bed Reactors". In Proceedings of the 7th International Conference on Discrete Element Methods, X. Li, Y. Feng, and G. Mustoe, eds., Springer Singapore, pp. 1183-1191.

[19] Maria, P., 2016. "Higher-Order Chebyshev Rational Approximation Method and Application to Burnup Equations". Nuclear Science and Engineering, 182(3), pp. 297-318. 